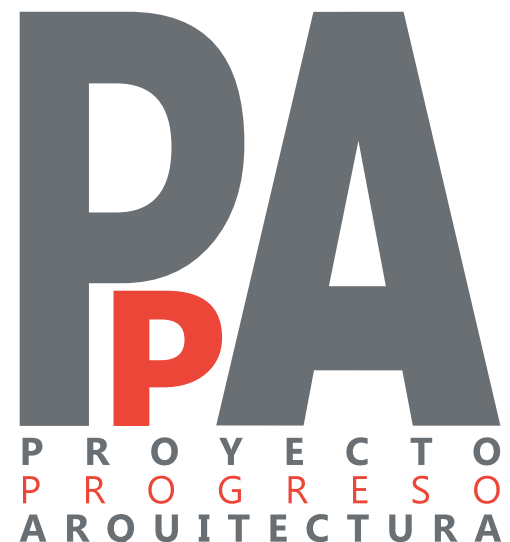

ARQUITECTURAS AMPLIADAS

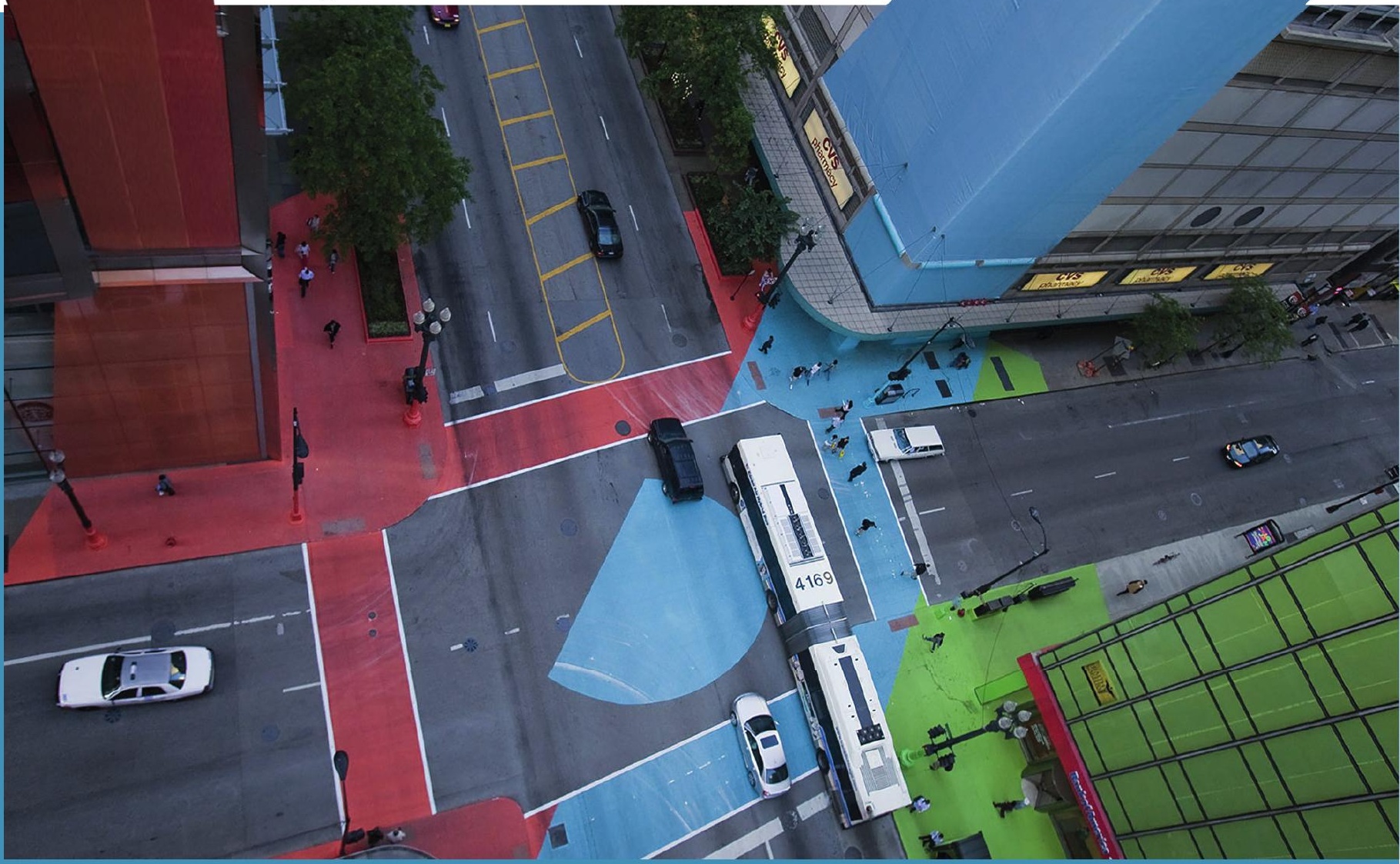




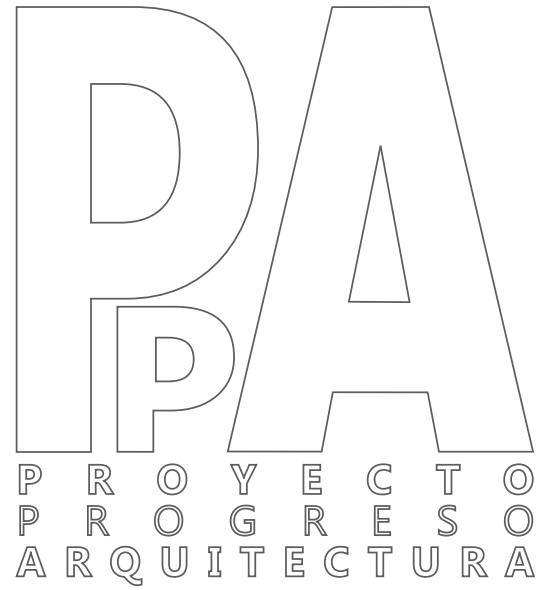

\section{ARQUITECTURAS AMPLIADA}

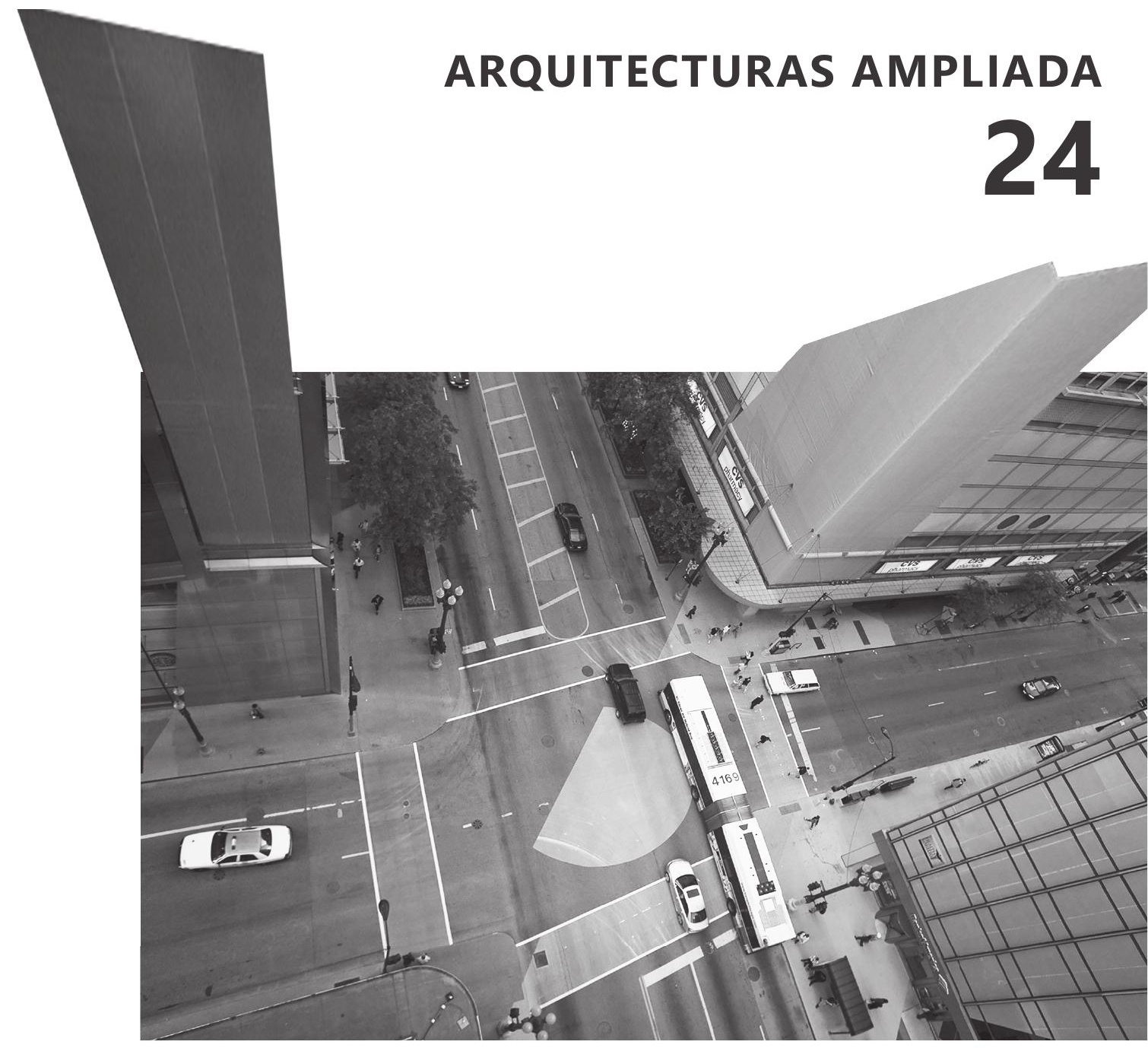

EDITORIAL UNIVERSIDAD DE SEVILLA AÑO 2019. ISSN 2171-6897 ISSNe 2173-1616 DOI: http://dx.doi.org/10.12795/ppa 


\section{REVISTA PROYECTO PROGRESO ARQUITECTURA}

N2/4

arquitecturas ampliadas
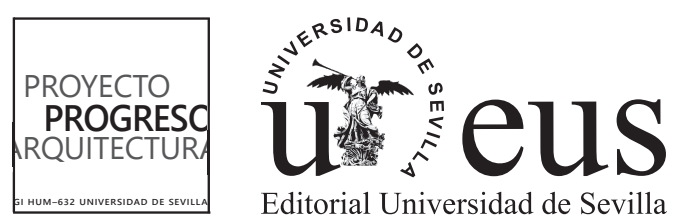


\section{arquitecturas ampliadas}

EDITA

Editorial Universidad de Sevilla. Sevilla

DIRECCIÓN CORRESPONDENCIA CIENTÍFICA

E.T.S. de Arquitectura. Avda Reina Mercedes, nº $241012-$

Sevilla.

Amadeo Ramos Carranza, Dpto. Proyectos Arquitectónicos.

e-mail: revistappa.direccion@gmail.com

\section{EDICIÓN ON-LINE}

Portal informático https://revistascientificas.us.es/index.php/ppa Portal informático Grupo de Investigación HUM-632

http://www. proyectoprogresoarquitectura.com

Portal informático Editorial Universidad de Sevilla http://www. editorial.us.es/

(c) EDITORIAL UNIVERSIDAD DE SEVILLA, 2019.

Calle Porvenir, 27. 41013 SEVILLA. Tfs. 954487447 / 954487451

Fax 954487443. [eus4@us.es] [http://www.editorial.us.es]

(c) TEXTOS: SUS AUTORES,

(C) IMÁGENES: SUS AUTORES Y/O INSTITUCIONES

DISEÑO PORTADA:

Rosa María Añón Abajas - Amadeo Ramos Carranza

En base a la fotografía: (C) Jessica Stockholder, cortesía de la artista y de Mitchell-Innes \& Nash, Nueva York

\section{DISEÑO PLANTILLA PORTADA-CONTRAPORTADA}

Miguel Ángel de la Cova Morillo-Velarde

DISEÑO PLANTILLA MAQUETACIÓN

Maripi Rodríguez

MAQUETACIÓN

Referencias Cruzadas

CORRECCION ORTOTIPOGRÁFICA

José Antonio Duarte

ISSN (ed. impresa): 2171-6897

ISSN-e (ed. electrónica): 2173-1616

DOI: http://dx.doi.org/10.12795/ppa

DEPÓSITO LEGAL: SE-2773-2010

PERIOCIDAD DE LA REVISTA: MAYO Y NOVIEMBRE

IMPRIME: PODIPRINT

Reservados todos los derechos. Ni la totalidad ni parte de esta revista puede reproducirse o transmitirse por ningún procedimiento electrónico o mecánico, incluyendo fotocopia, grabación magnética o cualquier almacenamiento de información y sistema de recuperación, sin permiso escrito de la Editorial Universidad de Sevilla.

Las opiniones y los criterios vertidos por los autores en los artículos firmados son responsabilidad exclusiva de los mismos. 


\section{DIRECCIÓN}

Dr. Amadeo Ramos Carranza. Escuela Técnica Superior de Arquitectura. Universidad de Sevilla. España

\section{SECRETARÍA}

Dra. Rosa María Añón Abajas. Escuela Técnica Superior de Arquitectura. Universidad de Sevilla. España

\section{EQUIPO EDITORIAL \\ Edición:}

Dr. Amadeo Ramos Carranza. Escuela Técnica Superior de Arquitectura. Universidad de Sevilla. España.

Dra. Rosa María Añón Abajas. Escuela Técnica Superior de Arquitectura. Universidad de Sevilla. España.

Dr. Francisco Javier Montero Fernández. Escuela Técnica Superior de Arquitectura. Universidad de Sevilla. España.

Dra. Esther Mayoral Campa. Escuela Técnica Superior de Arquitectura. Universidad de Sevilla. España.

Dr. Miguel Ángel de la Cova Morillo-Velarde. Escuela Técnica Superior de Arquitectura. Universidad de Sevilla. España.

Dr. Germán López Mena. Escuela Técnica Superior de Arquitectura. Universidad de Sevilla. España.

Dra. Gloria Rivero Lamela. Escuela Técnica Superior de Arquitectura. Universidad de Sevilla. España.

Juan José López de la Cruz. Escuela Técnica Superior de Arquitectura. Universidad de Sevilla. España.

Guillermo Pavón Torrejón. Escuela Técnica Superior de Arquitectura. Universidad de Sevilla. España.

Externos edición (asesores):

Dr. José Altés Bustelo. Escuela Técnica Superior de Arquitectura. Universidad de Valladolid. España.

Dr. Carlos Arturo Bell Lemus. Facultad de Arquitectura. Universidad del Atlántico. Colombia.

Dr. José de Coca Leicher. Escuela Técnica Superior de Arquitectura. Universidad Politécnica de Madrid. España. Dra. Patricia de Diego Ruiz. Escuela Técnica Supeiror de Arquitectura y Geodesia. Universidad Alcalá de Heranes. España.

Dr. Alfonso del Pozo y Barajas. Escuela Técnica Superior de Arquitectura. Universidad de Sevilla. España.

Dr. Jaume J. Ferrer Fores. Escola Tècnica Superior

d'Arquitectura de Barcelona. Universitat Politècnica de Catalunya. España.

Dra. Laura MArtínez Guereñu. El School of Architecture \& Design, IE University, Madrid; Segovia. España.

Dra. Clara Mejía Vallejo. Escuela Técnica Superior de Arquitectura. Universidad Politécnica de Valencia. España.

Dra. Luz Paz Agras. Escuela Técnica Superior de Arquitectura. Universidade da Coruña. España.

Dra. Marta Sequeira. CIAUD, Faculdade de Arquitectura da Universidade de Lisboa, Portugal.

\section{SECRETARÍA TÉCNICA}

Dra. Gloria Rivero Lamela. Escuela Técnica Superior de Arquitectura. Universidad de Sevilla. España.

\section{EDITORA Y COORDINACION CONTENIDOS CIENTÍFICOS DEL NÚMERO}

Dra. Rosa María Añón Abajas. Escuela Técnica Superior de Arquitectura. Universidad de Sevilla. España.

\section{COMITÉ CIÉNTIFICO}

Dr. Carlo Azteni. DICAAR. Dipartimento di Ingegneria Civile, Ambientale e Architettura. University Of Cagliari. Italia.

Dra. Maristella Casciato. GETTY Research Institute, GETTY, Los Angeles. Estados Unidos.

Dra. Anne Marie Châtelet. École Nationale Supérieure D'Architecture de Strasbourg (ENSAS). Francia.

Dr. Jean Louis Cohen. Institute of Fine Arts, New York University. Estados Unidos.

Dra. Josefina González Cubero. Escuela Técnica Superior de Arquitectura. Universidad de Valladolid. España.

Dr. José Manuel López Peláez. Escuela Técnica Superior de Arquitectura. Universidad Politécnica de Madrid. España.

Dra. Maite Méndez Baiges. Departamento de Historia del Arte. Universidad de Málaga. España.

Dr. Dietrich C. Neumann. Brown University In Providence, Ri (John Nicholas Brown Center For Public Humanities And Cultural Heritage). Estados Unidos.

Dr. Víctor Pérez Escolano. Catedrático Historia, Teoría y Composición Arquitectónicas. Escuela Técnica Superior de Arquitectura. Universidad de Sevilla. España.

Dr. Jorge Torres Cueco. Catedrático Proyectos Arquitectónicos. Escuela Técnica Superior de Arquitectura. Universitat Politècnica de València. España.

Dr. ir. Frank van der Hoeven, TU DELFT. Architecture and the Built Environment, Netherlands

\section{CORRESPONSALES}

Pablo de Sola Montiel. The Berlage Centre for Advanced Studies in Architecture and Urban Design. Paises Bajos.

Dr. Plácido González Martínez. Tongji University Caup (College Of architectura \& Urban Planing). Shangai, China.

Patrícia Marins Farias. Faculdade de Arquitetura. Universidade Federal da Bahia. Brasil.

Dr. Daniel Movilla Vega. Umeå School of Architecture. Umeå University. Suecia.

Dr. Pablo Sendra Fernández. The Bartlett School of Planning. University College London. Inglaterra.

Alba Zarza Arribas. Centro de Estudos Arnaldo Araújo, Porto. Portugal.

Dra. María Elena Torres Pérez. Facultad de Arquitectura. Universidad Autónoma de Yucatán, Mérida. México.

\section{TEXTOS VIVOS}

Juan José López de la Cruz. Escuela Técnica Superior de Arquitectura. Universidad de Sevilla. España.

Dr. Francisco Javier Montero Fernández. Escuela Técnica Superior de Arquitectura. Universidad de Sevilla. España. Dra. Esther Mayoral Campa. Escuela Técnica Superior de Arquitectura. Universidad de Sevilla. España. 


\section{SERVICIOS DE INFORMACIÓN}

\section{CALIDAD EDITORIAL}

La Editorial Universidad de Sevilla cumple los criterios establecidos por la Comisión Nacional Evaluadora de la Actividad Investigadora para que lo publicado por el mismo sea reconocido como "de impacto" (Ministerio de Ciencia e Innovación, Resolución 18939 de 11 de noviembre de 2008 de la Presidencia de la CNEAI, Apéndice I, BOE n² 282, de 22.11.08).

La Editorial Universidad de Sevilla forma parte de la U.N.E. (Unión de Editoriales Universitarias Españolas) ajustándose al sistema de control de calidad que garantiza el prestigio e internacionalidad de sus publicaciones.

PUBLICATION QUALITY

The Editorial Universidad de Sevilla fulfils the criteria established by the National Commission for the Evaluation of Research Activity (CNEAI) so that its publications are recognised as "of impact" (Ministry of Science and Innovation, Resolution 18939 of 11 November 2008 on the Presidency of the CNEAl, Appendix I, BOE No 282, of 22.11.08).

The Editorial Universidad de Sevilla operates a quality control system which ensures the prestige and international nature of its publications, and is a member of the U.N.E. (Unión de Editoriales Universitarias Españolas-Union of Spanish University Publishers).

Los contenidos de la revista PROYECTO, PROGRESO, ARQUITECTURA aparecen en:

bases de datos: indexación
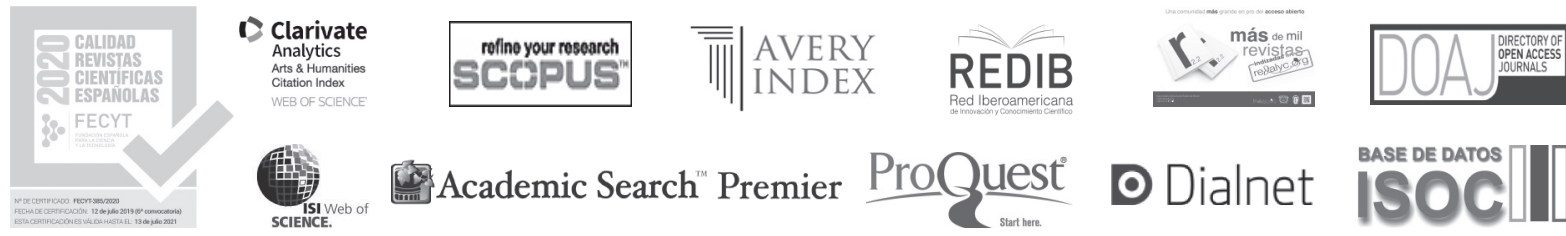

D Dialnet

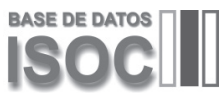

SELLO DE CALIDAD EDITORIAL FECYT 2019. RENOVADO 2020. (Cuartil C3)

WoS. Arts \& Humanities Citation Index

WoS. ESCl - Emerging Sources Citation Index

SCOPUS

AVERY. Avery Index to Architectural Periodicals

REBID. Red Iberoamericana de Innovación y Conocimiento Científico

REDALYC. Red de Revistas Científicas de América Latina y el Caribe, España y Portugal.

EBSCO. Fuente Académica Premier

EBSCO. Art Source

DOAJ, Directory of Open Access Journals

PROQUEST (Arts \& Humanities, full text)

DIALNET

ISOC (Producida por el CCHS del CSIC)

DRIJ. Directory of Research Journals Indexing

SJR (2019): 0.100, H index: 2

\section{catalogaciones: criterios de calidad}

RESH (Revistas Españolas de Ciencias Sociales y Humanidades).

Catálogos CNEAI (16 criterios de 19). ANECA (18 criterios de 21). LATINDEX (35 criterios sobre 36).

DICE (CCHS del CSIC, ANECA).

MIAR, Matriu d'Informació per a l'Avaluació de Revistes. IDCS 2018: 10,500. Campo ARQUITECTURA

CLASIFICACIÓN INTEGRADA DE REVISTAS CIENTÍFICAS (CIRC-CSIC): A

ERIHPLUS

SCIRUS, for Scientific Information.

ULRICH'S WEB, Global Serials Directory.

ACTUALIDAD IBEROAMERICANA.

\section{catálogos on-line bibliotecas notables de arquitectura:}

CLIO. Catálogo on-line. Columbia University. New York

HOLLIS. Catálogo on-line. Harvard University. Cambridge. MA

SBD. Sistema Bibliotecario e Documentale. Instituto Universitario di Architettura di Venezia

OPAC. Servizi Bibliotecari di Ateneo. Biblioteca Centrale. Politecnico di Milano

COPAC. Catálogo colectivo (Reino Unido)

SUDOC. Catálogo colectivo (Francia)

ZBD. Catálogo colectivo (Alemania)

REBIUN. Catálogo colectivo (España)

OCLC. WorldCat (Mundial) 
EVALUACIÓN EXTERNA POR PARES Y ANÓNIMA.

El Consejo Editorial remitirá el artículo a dos expertos revisores anónimos dentro del campo específico de investigación y crítica de arquitectura, según el modelo doble ciego.

El director de la revista comunicará a los autores el resultado motivado de la evaluación por correo electrónico, en la dirección que éstos hayan utilizado para enviar el artículo. El director comunicará al autor principal el resultado de la revisión (publicación sin cambios; publicación con correcciones menores; publicación con correcciones importantes; no aconsejable para su publicación), así como las observaciones y comentarios de los revisores.

Si el manuscrito ha sido aceptado con modificaciones, los autores deberán reenviar una nueva versión del artículo, atendiendo a las demandas y sugerencias de los evaluadores externos. Los artículos con correcciones importantes serán remitidos al Consejo Asesor para verificar la validez de las modificaciones efectuadas por el autor. Los autores pueden aportar también una carta al Consejo Editorial en la que indicarán el contenido de las modificaciones del artículo. Los artículos con correcciones importantes serán remitidos al Consejo Asesor para verificar la validez de las modificaciones efectuadas por el autor.

\section{DECLARACIÓN ÉTICA SOBRE PUBLICACIÓN Y MALAS PRÁCTICAS}

La revista PROYECTO, PROGRESO, ARQUITECTURA (PPA) está comprometida con la comunidad académica en garantizar la ética y calidad de los artículos publicados. Nuestra revista tiene como referencia el Código de Conducta y Buenas Prácticas que, para editores de revistas científicas, define el COMITÉ DE ÉTICA DE PUBLICACIONES (COPE).

Así nuestra revista garantiza la adecuada respuesta a las necesidades de los lectores y autores, asegurando la calidad de lo publicado, protegiendo y respetando el contenido de los artículos y la integridad de los mismo. El Consejo Editorial se compromete a publicar las correcciones, aclaraciones, retracciones y disculpas cuando sea preciso.

En cumplimiento de estas buenas prácticas, la revista PPA tiene publicado el sistema de arbitraje que sigue para la selección de artículos así como los criterios de evaluación que deben aplicar los evaluadores externos -anónimos y por pares, ajenos al Consejo Editorial-. La revista PPA mantiene actualizados estos criterios, basados exclusivamente en la relevancia científica del artículo, originalidad, claridad y pertinencia del trabajo presentado.

Nuestra revista garantiza en todo momento la condifencialidad del proceso de evaluación: el anonimato de los evaluadores y de los autores; el contenido evaluado; los informes razonados emitidos por los evaluadores y cualquier otra comunicación emitida por los consejos Editorial, Asesor y Científico si así procediese.

Igualmente quedan afectados de la máxima confidencialidad las posibles aclaraciones, reclamaciones o quejas que un autor desee remitir a los comités de la revista o a los evaluadores del artículo.

La revista PROYECTO, PROGRESO, ARQUITECTURA (PPA) declara su compromiso por el respeto e integridad de los trabajos ya publicados. Por esta razón, el plagio está estrictamente prohibido y los textos que se identifiquen como plagio o su contenido sea fraudulento, serán eliminados o no publicados por la revista PPA. La revista actuará en estos casos con la mayor celeridad posible. Al aceptar los términos y acuerdos expresados por nuestra revista, los autores han de garantizar que el artículo y los materiales asociados a él son originales o no infringen derechos de autor. También los autores tienen que justificar que, en caso de una autoría compartida, hubo un consenso pleno de todos los autores afectados y que no ha sido presentado ni publicado con anterioridad en otro medio de difusión.

\section{EXTERNAL ANONYMOUS PEER REVIEW.}

Editorial Board will be sent to two anonymous experts, within the specific field of architectural investigation and critique, for a double blind review.

The Director of the journal will communicate the result of the reviewers evaluations to the authors by electronic mail, to the address used to send the article. The Director will communicate the result of the review (publication without changes; publication with minor corrections; publication with significant corrections; its publication is not advisable), as well as the observations and comments of the reviewers, to the main author.

If the manuscript has been accepted with modifications, the authors will have to resubmit a new version of the article, addressing the requirements and suggestions of the external reviewers. The articles with corrections will be sent to Advisory Board for verification of the validity of the modifications made by the author. The authors can also send a letter to the Editorial Board, in which they will indicate the content of the modifications of the article.

\section{ETHICS STATEMENT ON PUBLICATION AND BAD PRACTICES} PROYECTO, PROGRESO ARQUITECTURA (PPA) makes a commitment to the academic community by ensuring the ethics and quality of its published articles. As a benchmark, our journal uses the Code of Conduct and Good Practices which, for scientific journals, is defined for editors by the PUBLICATION ETHICS COMMITTEE (COPE).

Our journal thereby guarantees an appropriate response to the needs of readers and authors, ensuring the quality of the published work, protecting and respecting the content and integrity of the articles. The Editorial Board will publish corrections, clarifications, retractions and apologies when necessary.

In compliance with these best practices, PPA has published the arbitration system that is followed for the selection of articles as well as the evaluation criteria to be applied by the anonymous, external peer-reviewers. PPA keeps these criteria current, based solely on the scientific importance, the originality, clarity and relevance of the presented article.

Our journal guarantees the confidentiality of the evaluation process at all times: the anonymity of the reviewers and authors; the reviewed content; the reasoned report issued by the reviewers and any other communication issued by the editorial, advisory and scientific boards as required.

Equally, the strictest confidentiality applies to possible clarifications, claims or complaints that an author may wish to refer to the journal's committees or the article reviewers.

PROYECTO, PROGRESO ARQUITECTURA (PPA) declares its commitment to the respect and integrity of work already published. For this reason, plagiarism is strictly prohibited and texts that are identified as being plagiarized, or having fraudulent content, will be eliminated or not published in PPA. The journal will act as quickly as possible in such cases. In accepting the terms and conditions expressed by our journal, authors must guarantee that the article and the materials associated with it are original and do not infringe copyright. The authors will also have to warrant that, in the case of joint authorship, there has been full consensus of all authors concerned and that the article has not been submitted to, or previously published in, any other media. 
EVALUADORES EXTERNOS (publicación cada cuatro números, dos años). NÚMEROS 21 a 24 (incluidos)

Álvarez Álvarez, Darío. Catedrático de Universidad / Departamento de Teoría de la Arquitectura y Proyectos Arquitectónicos / ETS Arquitectura / Universidad de Valladolid / España.

Arrieta Berdasco, Valentín. Doctor Arquitecto, Profesor Asociado / Departamento de Teoría de la Arquitectura y Proyectos Arquitectónicos / ETS Arquitectura / Universidad de Valladolid / España.

Bardí i Milá, Berta. Profesora Asociada doctora / / Departamento de Projectes Arquitectònics / ETS Arquitectura / Universitat Politècnica de Catalunya, Barcelona Tech / España.

Bergera Serrano, Iñaki. Titular de Universidad / Unidad Predepartamental de Arquitectura / Área Proyectos Arquitectónicos / El y Arquitectura / Universidad de Zaragoza / España.

Bobbink, Inge. Dr. ir. Architecture / Section of landscape architecture / TU Delft / Países Bajos.

Burriel Bielza, Luis. Profesor Titular / École Nationale Supérieure d'Architecture de Paris-Belleville / Francia

Calatrava Escobar, Juan. Catedrático de Universidad / Departamento de Construcciones Arquitectónicas / ETS Arquitectura / Universidad de Granada / España.

Castellanos Gómez, Raúl. Titular de Universidad / Departamento de Proyectos Arquitectónicos / ETS Arquitectura / Universidad Politécnica de Valencia / España.

Centellas Soler, Miguel. Titular de Universidad / Departamento de Arquitectura y Tecnología de la Edificación / ETS Arquitectura y Edificación / Universidad Politécnica de Cartagena / España.

Chías Navarro, Pilar. Catedrática de Universidad / Departamento de Arquitectura / ETS Arquitectura y Geodesia / Universidad de Alcalá de Henares / España.

de Diego Ruiz, Patricia. Doctora arquitecta, Profesora Asociada / Departamento de Arquitectura / ETS Arquitectura y Geodesia / Universidad de Alcalá de Henares / España.

de la Iglesia Salgado, Félix. Profesor Contratado Doctor / Departamento de Proyectos Arquitectónicos / ETS Arquitectura / Universidad de Sevilla / España.

de la O Cabrera, Manuel Rodrigo. Doctor Arquitecto, Profesor Asociado / Departamento de Composición Arquitectónica / ETS Arquitectura / Universidad Politécnica de Madrid / España.

Delgado Orusco, Eduardo. Profesor Ayudante Doctor / Departamento de Arquitectura. Área de Proyectos Arquitectónicos / Escuela de Ingeniería y Arquitectura / Universidad de Zaragoza / España.

Deltell Pastor, Juan. Titular de Universidad / Departamento de Proyectos Arquitectónicos / ETS Arquitectura / Universitat Politècnica de València / España.

Diañez Rubio, Pablo. Titular de Universidad / Departamento de Proyectos Arquitectónicos / ETS Arquitectura / Universidad de Sevilla / España.

Díaz Segura, Alfonso. Titular de Universidad / Proyectos, Teoría y Técnica del Diseño y la Arquitectura / ETS Arquitectura / Universidad CEU Cardenal Herrera, Valencia / España.

Domingo Calabuig, Débora. Titular de Universidad / Departamento de Proyectos Arquitectónicos / ETS Arquitectura / Universidad Politécnica de Valencia / España.

Fernández Fariña, Almudena. Profesora Contratada Doctora / Departamento de Pintura / Facultad de Bellas Artes / Universidad de Vigo / España.

Fernández-Trapa de Isasi, Justo. Catedrático de Universidad / Departamento de Proyectos Arquitectónicos / ETS Arquitectura / Universidad Politécnica de Madrid / España.

García Escudero, Daniel. Dr. Arquitecto, Profesor Lector / Departamento de Projectes Arquitectònics / ETS Arquitectura / Universitat Politècnica de Catalunya, Barcelona Tech / España.

González Cubero, Josefina. Titular de Universidad / Departamento de Teoría de la Arquitectura y Proyectos Arquitectónicos / ETS Arquitectura / Universidad de Valladolid / España.

González Fraile, Eduardo. Catedrático de Universidad / Departamento de Teoría de la Arquitectura y Proyectos Arquitectónicos / ETS Arquitectura / Universidad de Valladolid / España.

Gorostiza López, Jorge. Doctor Arquitecto. Cineasta / España.

Hernández Moreno, Silverio. Profesor investigador titular / Facultad de Arquitectura y Diseño / Universidad Autónoma del Estado de México / México.

Labarta Aizpún, Carlos. Titular de Universidad / Unidad Predepartamental de Arquitectura / Área Proyectos Arquitectónicos / Escuela de Ingeniería y Arquitectura / Universidad de Zaragoza / España.

Lizondo Sevilla, Laura. Titular de Universidad / Departamento de Proyectos Arquitectónicos / ETS Arquitectura / Universidad Politécnica de Valencia / España.

Llopis Verdú, Jorge. Catedrático de Universidad / Departamento de Expresión Gráfica Arquitectónica / ETS Arquitectura / Universidad Politécnica de Valencia / España.

López Bahut, Emma. Profesora Contratada Doctora / Departamento de Proyectos arquitectónicos, Urbanismo y Composición / ETS Arquitectura / Universidade da Coruña / España.

López Fernández, Andrés. Titular de Universidad / Departamento de Proyectos Arquitectónicos / ETS Arquitectura / Universidad de Sevilla / España.

Loren Méndez, Mar. Catedrática de Universidad / Departamento de Historia, Teoría y Composición Arquitectónica / ETS Arquitectura / Universidad de Sevilla / España.

Maino Ansaldo, Sandro. Doctor Arquitecto / Departamento Arquitectura / Universidad Técnica Federico Santa María / Chile.

Mària i Serrano, Magda. Profesora Contratada Doctor / Departamento de Projectes Arquitectònics / ETS Arquitectura del Vallès / Universitat Politècnica de Catalunya / España

Marson, Anna. Profesora Ordinario / Dipartimento di culture del progetto / Istituto Universitario di Architettura di Venezia / Università di Venezia / Italia.

Martínez Díaz, Ángel. Titular de Universidad / Departamento de Ideación Gráfica Arquitectónica / ETS Arquitectura / Universidad Politécnica de Madrid / España. 
Mejía Vallejo, Clara. Titular de Universidad / Departamento de Proyectos Arquitectónicos / ETS Arquitectura / Universidad Politécnica de Valencia / España.

Mercader Moyano, Pilar. Titular de Universidad / Departamento de Proyectos Arquitectónicos / ETS Arquitectura / Universidad de Sevilla / España.

Mercé Hospital, José María. Catedrático de Universidad / Departamento de Proyectos Arquitectónicos / ETS Arquitectura y Geodesia / Universidad Alcalá de Henares / España.

Merí de la Maza, Ricardo. Titular de Universidad / Departamento de Proyectos Arquitectónicos / ETS Arquitectura / Universidad Politécnica de Valencia / España.

Mestre Martínez, Nieves. Doctora arquitecta, Profesora Asociada / Departamento de Proyectos Arquitectónicos / ETS Arquitectura / Universidad Politécnica de Madrid / España.

Millán Gómez, Antonio. Catedrático de Universidad / Departamento d’Expressió Gràfica Arquitectònica I / ETS Arquitectura del Vallès / Universitat Politècnica de Catalunya / España.

Moreno Pérez, José Ramón. Titular de Universidad / Dpto. Historia, Teoría y Composición Arquitectónica / ETS Arquitectura / Universidad de Sevilla / España.

Nijhuis, Steffen. Associate Professor. Head of Landscape Architecture Research / Section of Landscape Architecture / Department of Urbanism / Faculty of Architecture and the Built Environment / TU Delft / Países Bajos.

Ojeda Rivera, Juan Francisco. Catedrático de Universidad / Departamento de Geografía, Historia y Filosofía / Universidad Pablo de Olavide, Sevilla / España.

Paz-Agras, Luz. Profesora Ayudante doctor / Departamento de Proyectos Arquitectónicos, Urbanismo y Composición. Área de Composición Arquitectónica / ETS Arquitectura / Universidad de A Coruña / España

Pérez Moreno, Lucía C. Titular de Universidad / Departamento de Arquitectura. Área de Composición Arquitectónica / Escuela de Ingeniería y Arquitectura / Universidad de Zaragoza / España.

Pina Lupiañez, Rafael. Profesor Contratado Doctor / Departamento de Proyectos Arquitectónicos / ETS Arquitectura / Universidad Politécnica de Madrid / España

Oliverira do Nascimento, Francisco. Professor Auxiliar / Faculdade de Arquitetura / Universidade de Lisboa / Portugal.

Rovira Llobera, Teresa. Titular de Universidad / Departamento de Projectes Arquitectònics / ETS Arquitectura / Universitat Politècnica de Catalunya, Barcelona Tech / España.

Ruiz Rosa, José Antonio. Catedrático de Universidad / Departamento de Expresión Gráfica Arquitectónica / ETS Arquitectura / Universidad de Sevilla. / España.

Sabaté Bel, Joaquín. Catedrático de Universidad / Departamento de Urbanismo y Ordenación del Territorio / ETS Arquitectura / Universitat Politècnica de Catalunya, Barcelona Tech / España

Sainz Gutiérrez Victoriano. Titular de Universidad / Departamento de Urbanismo y Ordenación del Territorio / ETS Arquitectura / Universidad de Sevilla / España

Sánchez Lampreave, Ricardo. Profesor Titular / Área de Composición Arquitectónica / Escuela de Ingeniería y Arquitectura / Universidad de Zaragoza / España.

Sambricio R. Echegaray, Carlos. Catedrático de Universidad / Departamento de Composición Arquitectónica / ETS Arquitectura / Universidad Politécnica de Madrid / España. / España.

Santamarina-Macho, Carlos. España. Doctor Arquitecto, Profesor Asociado / Departamento de Teoría de la Arquitectura y Proyectos Arquitectónicos / ETS Arquitectura / Universidad de Valladolid / España

Senra Fernández-Miranda, Ignacio. Doctor Arquitecto, Profesor Asociado / Departamento de Proyectos Arquitectónicos / ETS Arquitectura / Universidad Politécnica de Madrid / España.

Sentieri Omarrementeria, Carla. Titular de Universidad / Departamento de Proyectos Arquitectónicos / ETS Arquitectura / Universidad Politécnica de Valencia / España.

Sequeira Marta. Professora doctora / ISCTE - Instituto Universitário de Lisboa/ Universidade Autónoma de Lisboa / CIAUD - Faculdade de Arquitectura da Universidade de Lisboa / Portugal.

Sola Alonso, José Ramón. España. Profesor Contratado Doctor / Departamento de Teoría de la Arquitectura y Proyectos Arquitectónicos / ETS Arquitectura / Universidad de Valladolid / España.

Trillo Martínez, Valentín. Doctor arquitecto Profesor Asociado / Departamento de Proyectos Arquitectónicos / ETS Arquitectura / Universidad de Sevilla / España.

Villalobos Alonso, Daniel. Titular de Universidad / Departamento de Teoría de la Arquitectura y Proyectos Arquitectónicos / ETS Arquitectura / Universidad de Valladolid / España.

Verde Zein, Ruth. Doctora arquitecto e investigadora / Facultad de Arquitectura y Urbanismo / Universidad Presbiteriana Mackenzie. São Paulo / Brasil.

\section{ESTADÍSTICAS PUBLICACIÓN (publicación cada cuatro números, dos años). NÚMEROS 1 a 20 (incluidos)}

Total artículos recibidos: 546

Total artículos publicados: 199 (36,45\%)

Total artículos rechazados: $347(63,55 \%)$

Total artículos publicados de autores pertenecientes a los diferentes consejos o comités organizadores de la revista y Grupo de Investigación "proyecto, progreso, arquitectura"(endogamia): 20 (10,05\%)

Total artículos publicados de autores pertenecientes a la Universidad de Sevilla: 53 (26,63\%)

Total artículos publicados de autores externos a los diferentes consejos o comités organizadores de la revista y Grupo de Investigación

"proyecto, progreso, arquitectura": 179 (89,95\%)

Total artículos publicados de autores extranjeros: 17 (8,54\%) 


\section{arquitecturas ampliadas}

índice

editorial

DESPEJAR LA ARQUITECTURA, LIBERAR EL ESPACIO Y AMPLIAR CONCEPTOS / UNCLUTTER ARCHITECTURE, FREE UP SPACE AND EXPAND CONCEPTS

Rosa María Añón-Abajas - (DOI: http://dx.doi.org/10.12795/ppa.2021.i24.10)

entre líneas

PAISAJES ARQUITECTÓNICOS Y MEMORIAS DE LA CIUDAD / ARCHITECTURAL LANDSCAPES AND MEMORIES OF THE CITY

Darío Álvarez Álvarez - (D0l: http://dx.doi.org/10.12795/ppa.2021.i24.01)

artículos

LINAZASORO EN REIMS. EL ESPACIO PÚBLICO COMO MEMORIA DEL LUGAR / LINAZASORO IN REIMS. THE PUBLIC SPACE AS THE MEMORY OF THE PLACE

Victoriano Sainz Gutiérrez - (DOl: http://dx.doi.org/10.12795/ppa.2021.i24.02)

EDITAR VS. CONSTRUIR: UNA ECOLOGÍA DE LO INVISIBLE. AMPLIFICAR LA COMPRENSIÓN DE LAS TÉCNICAS DE PROYECTO / EDITING VS. BUILDING: AN ECOLOGY OF THE INVISIBLE. AMPLIFYING THE UNDERSTANDING OF ARCHITECTURAL DESIGN TECHNIQUES

Paula Victoria Álvarez Benítez - (DOI: http://dx.doi.org/10.12795/ppa.2021.i24.03)

CUANDO LA PINTURA AMPLÍA LA ARQUITECTURA: INTERVENCIONES REALIZADAS EN EL ESPACIO PÚBLICO / WHEN PAINTING ENHANCES ARCHITECTURE: INTERVENTIONS IN A PUBLIC SETTING Aurora Alcaide-Ramírez; Ana Ruiz-Abellón - (D0l: http://dx.doi.org/10.12795/ppa.2021.i24.04)

UN EDIFICIO INVISIBLE. NUEVO AULARIO DE LA FACULTAD DE DERECHO DE LA UNIVERSIDAD DE ZARAGOZA (1983-1996) / AN INVISIBLE BUILDING. NEW LECTURE ROOM BUILDING OF THE FACULTY OF LAW OF THE UNIVERSITY OF ZARAGOZA (1983-1996)

Luis Miguel Lus-Arana; Lucía Carmen Pérez-Moreno - (D0l: http://dx.doi.org/10.12795/ppa.2021.i24.05)

ARQUITECTURAS AMPLIADAS. EL PABELLÓN DE EXPOSICIONES EN LA CASA DE CAMPO DE MADRID) / EXPANDED ARCHITECTURES. THE EXHIBITION PAVILION AT THE CASA DE CAMPO IN MADRID José de Coca Leicher - (DOI: http://dx.doi.org/10.12795/ppa.2021.i24.06)

reseña bibliográfica TEXTOS VIVOS

RAFAEL MONEO VALLÉS: LA VIDA DE LOS EDIFICIOS. LA MEZQUITA DE CÓRDOBA, LA LONJA DE SEVILLA Y UN CARMEN EN GRANADA

Víctor Pérez Escolano - (DOl: http://dx.doi.org/10.12795/ppa.2021.i24.07)

FRANCISCO DE GRACIA: CONSTRUIR EN LO CONSTRUIDO. LA ARQUITECTURA COMO MODIFICACIÓN

Pablo Diañez Rubio - (DOl: http://dx.doi.org/10.12795/ppa.2020.i24.08)

FRÉDÉRIC DRUOT, ANNE LACATON \& JEAN-PHILIPPE VASSAL PLUS: LA VIVIENDA COLECTIVA. TERRITORIO DE EXCEPCIÓN

Javier Terrados Cepeda - (DOI: http://dx.doi.org/10.12795/ppa.2021.i24.09) 


\title{
EDITAR VS. CONSTRUIR: UNA ECOLOGÍA DE LO INVISIBLE. AMPLIFICAR LA COMPRENSIÓN DE LAS TÉCNICAS DE PROYECTO
}

\author{
EDITING VS. BUILDING: AN ECOLOGY OF THE INVISIBLE. AMPLIFYING THE \\ UNDERSTANDING OF ARCHITECTURAL DESIGN TECHNIQUES
}

Paula Victoria Álvarez Benítez (https://orcid.org/0000-0002-5628-4060)

RESUMEN Este artículo persigue una amplificación de la comprensión de las técnicas de arquitectura, vinculándolas a una "ecología de lo invisible": la atención prestada a variables cualitativas existentes en el contexto, apenas perceptibles y a menudo desestimadas por los regímenes de valor asentados. Este proceder -que podría ser rastreado en el diseño arquitectónico a lo largo de la historia- ha adquirido un valor nuevo, tras la crisis económico-financiera, como crítica a los modelos de desarrollo que dominaron en el cambio de siglo, lo cual también dificulta su comprensión. Para aclarar este punto, se analizan sus claves en tres proyectos fechados en los años precedentes a la crisis: la propuesta de Cedric Price para el concurso Design of Cities en Manhattan (1998), la remodelación de la plaza Léon Aucoc (1996) y la Escuela de Administración de Empresas (2006), ambas en Burdeos, de Lacaton \& Vassal. Si los dos primeros han sido leídos como formas de "no intervención", asociados a una renuncia a diseñar y construir, el tercero escapa a esta lectura, lo cual nos ayudará a reconsiderarlos en clave propositiva. La metodología de análisis se fija en los proyectos y en cómo han sido mediados en diversos canales y para diferentes públicos, desde las revistas especializadas a las "imágenes pobres" compartidas en las aplicaciones web de servidores de mapas. El análisis evidencia el papel crucial de la edición que, al privilegiar ciertos discursos, orienta consecuentemente las prácticas.

PALABRAS CLAVE cualidades imperceptibles; bienestar psicológico; mediaciones culturales; contexto; visibilidad; técnicas de proyecto

SUMMARY This article seeks to expand understanding of architectural design techniques, linking them to an "ecology of the invisible": the attention to qualitative variables existing in the context, barely perceptible and often dismissed by value regimes in place. Following the economic-financial crisis, this procedure - which could be traced to architectural design throughout history - has acquired a new value, as a critique of the development models which predominated at the turn of the century, and also hindering its understanding. To clarify this point, we discuss the keys of this procedure in three projects pre-dating the crisis: Cedric Price's proposal for the Design of Cities contest in Manhattan (1998), as well as the remodelling of Léon Aucoc Square (1996), and the School of Business Administration (2006), both in Bordeaux and by Lacaton \& Vassal. While the first two have been interpreted as forms of "non-intervention" associated with a renunciation of design and construction, the last case has not, leading us to reconsider these examples in a propositional manner. The analysis methodology focuses on projects and how they have been shaped across channels and for different audiences, from specialized journals to the "poor images" shared in map server web applications. This analysis highlights the crucial role of editing, which subsequently guides architectural practices by prioritizing certain discourses over others. KEY WORDS imperceptible qualities; psychological well-being; cultural mediations; context; visibility; architectural design techniques 


\section{INTRODUCCIÓN}

Nueva York, 1998. Apenas ha transcurrido un año de la inauguración del edificio que da nombre a la "década de Bilbao"1. La IFCCA convoca The CCA Competition for the Design of the Cities, un concurso internacional de ideas para mejorar la ciudad a través de la arquitectura². El objeto es la recualificación urbana de una extensa área de Manhattan ocupada por antiguas vías férreas abandonadas, con salida natural de carga y descarga al río Hudson. Una maraña de infraestructuras de transporte ocupa gran parte del solar: vías del tren, pasos superiores de autopistas, entradas a túneles, estacionamiento de autobuses... Los convocantes animan a los participantes a ir más allá de la convención e imaginar nuevas formas de experiencia urbana que dieran respuesta a un problema compartido por muchas ciudades: los vacíos liberados por las vastas infraestructuras de transporte obsoletas o en decadencia y aisladas de la vida urbana. Pero había algo más en juego. Según Herbert Muschamp, crítico de arquitectura para The New York Times, "Ios funcionarios de la ciudad ya habian definido el emplazamiento como el próximo gran corredor de desarrollo de la ciudad"3. Haciendo balance de las cinco propuestas finalistas, entonces expuestas al público, escribe: "Con la excepción del Sr. Price, Ios finalistas comparten algunos rasgos comunes. Todos utilizan curvas u ondas para separar el área del sitio de la regularidad circundante de la grilla de Manhattan. Con diversos grados de holgura, adoptan el enfoque megaestructural: unir las actividades urbanas dentro de un marco arquitectónico amplio y completo [...]"4.

En efecto, la propuesta ganadora de Peter Eisenman opta, como otros tres finalistas, por un gran conjunto de

1. Robert Campbell acuñó este término para designar el periodo comprendido entre la inauguración del Guggenheim de Bilbao (1997) y el estallido de la burbuja inmobiliaria (2008). CAMPBELL, R. Marking the End of "The Bilbao Decade": Times Dictate a Shift Away from Vanity Projects. En: Boston Globe, 2009, vol. 11, p. 49-71.

2. Ver: https://www.cca.qc.ca/en/archives/226652/ifcca-prize-competition-for-the-design-of-cities-fonds

3. MUSCHAMP, Herbert. Critic's Notebook; Design Fantasies for a Strip of the West Side. The New York Times, 18 de octubre de 1999. [Consulta: 30-09-2020]. Disponible en: https://www.nytimes.com/1999/10/18/arts/critic-s-notebook-design-fantasies-for-a-strip-of-the-west-side.html 4. Ídem. 


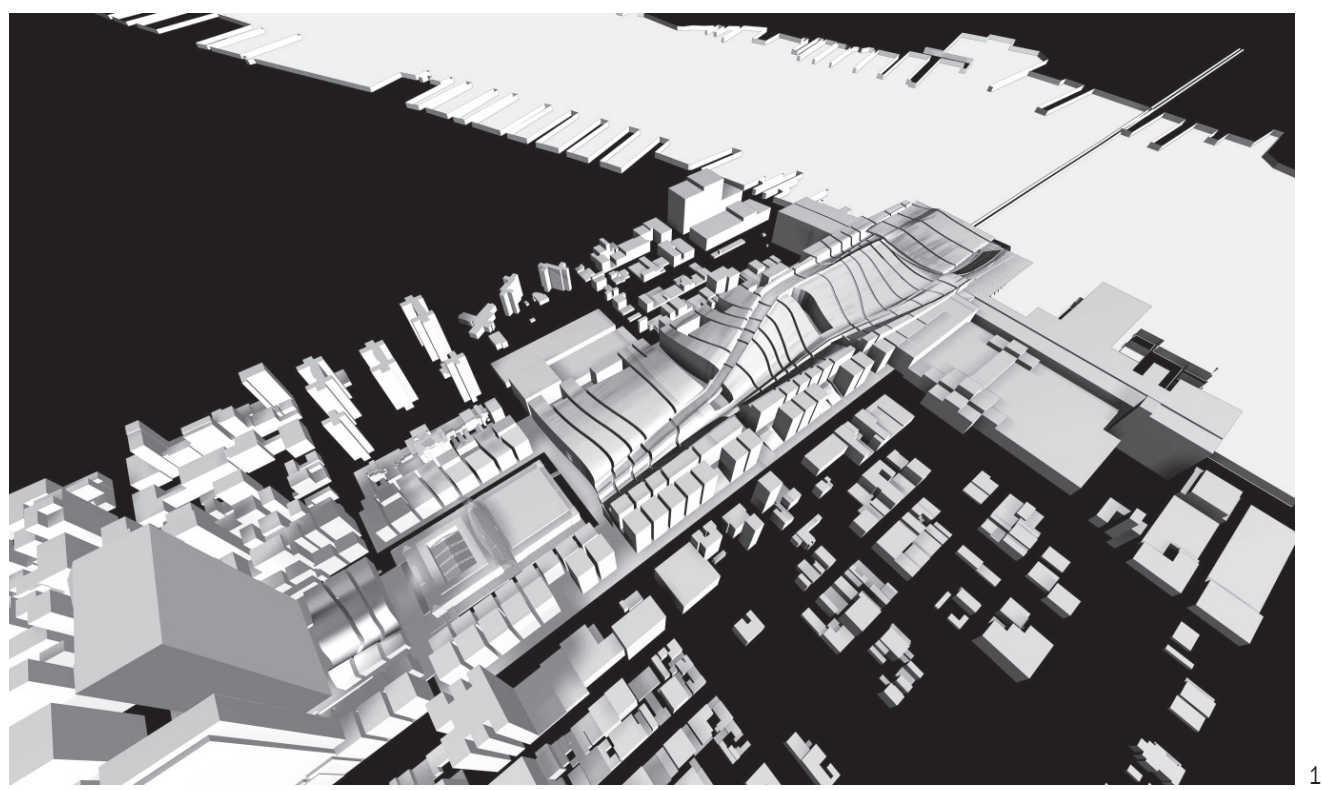

programas mixtos y gran escala que colmataba el solar, generando imágenes impactantes y persuasivas ${ }^{5}$. Descrita por el arquitecto como "el primer icono urbano del nuevo milenio", se formaliza como un conjunto escultórico de sensuales superficies onduladas que suben del plano horizontal al rascacielos monumental que remata la intervención, supuestamente evocando la presencia del Hudson ${ }^{6}$ (figura 1). Se trata de una de muchas intervenciones telegénicas proyectadas para generar capital simbólico a partir del impacto visual y la espectacularidad formal de las soluciones técnicas. Aunque nunca llegó a construirse, aquel mismo año Eisenman ganó con una estrategia similar otro concurso, la Ciudad de la Cultura de Galicia, "una especie de isla delirante" totalmente separada de la ciudad de Santiago y "sin infraestructura pública de conexión con ella"?.

Este concurso es recordado hoy, sin embargo, por la propuesta de Cedric Price ${ }^{8}$. En el momento de lanzamiento de la arquitectura telegénica como motor económico global, el arquitecto británico se desmarca, optando por poner en valor la presencia y el disfrute de las cualidades ambientales y sensuales que descubre en el lugar. Toda la propuesta gravita en torno a la revalorización de la brisa fresca proveniente del Hudson que cruza el solar y de las vistas abiertas, escasas en un Manhattan congestionado (figura 2). Se implica ingeniosamente con lo existente para reclamar el valor del proyecto arquitectónico como cuidado del bienestar psicológico del habitante y, por tanto, su salud, aspectos que el "urbanismo de enclave" tiende a borrar del imaginario de lo valioso. El lema de su propuesta, "Un pulmón para el Midtown de Manhattan", adquiere hoy nuevas resonancias tras la crisis desencadenada por el evento COVID-19. Su motivación profunda era amplificar el alcance de la imaginación proyectual, algo que hoy se ha convertido en una exigencia.

Price, en su crítica a las premisas asumidas en torno al papel de la arquitectura como instrumento de mejora urbana, no estuvo solo. Poco antes, Lacaton \& Vassal, en su proyecto para la plaza de Léon Aucoc (1996), proponía una estrategia basada en la atención y el cuidado de valores existentes. Ambas propuestas han sido reivindicadas tras la crisis del 2008 como estrategia de "nointervención" o "antiarquitectura"9, rescatadas por su valor crítico en relación con los excesos de la arquitectura más mediática de aquellos años. Esta lectura tiene un

5. Los otros finalistas fueron Thomas Mayne (Morphosis), Reiser + Umemoto RUR Architecture, Ben van Berkel y Caroline Boss.Muschamp. MUSCHAMP, H. op. cit. supra, nota 3.

6. Disponible en: https://eisenmanarchitects.com/IFCCA-Prize-Competition-for-the-Design-of-Cities-1999

7. PIZZA, Antonio. Peter Eisenman y la Ciudad de Cultura de Galicia, 1999-2011. En: DC Papers, revista de crítica y teoría de la arquitectura, 2010, n. ${ }^{\circ} 19$, pp. $37-56$.

8. PRICE, Cedric. Re: Cp. Luxemburgo: Springer Science \& Business Media, 2003, pp. 47-53.

9. Ver, por ejemplo, GARCÍA-GERMÁN, Jacobo. Estrategias operativas en arquitectura. Madrid: Nobuko, 2012, pp. 242-265.; LÓPEZ UJAQUE, José Manuel. Prefiriendo hacer (casi) nada en arquitectura: postproducción a través de cuatro declinaciones activamente perezosas. Director: Federico Soriano Peláez. Tesis doctoral. ETS Arquitectura (Universidad Politécnica de Madrid), 2017. 
1. Perspectiva urbana (render) del complejo y relación con la fábrica urbana. Ejsenman Architects. Propuesta ganadora del concurso Design of the Cities. IFCCA Prize Competition for the Design of Cities fonds. Canadian Centre for Architecture. 2. Cedric Price. A Lung for Midtown Manhattan, 1998. Vista en perspectiva mirando al este desde el río Hudson. Fotocopia sobre papel superpuesto con dibujo a tinta, grafito y lápiz de color sobre papel translúcido, 29,7 × $42 \mathrm{~cm}$. Cedric Price fonds. Canadian Centre for Architecture.

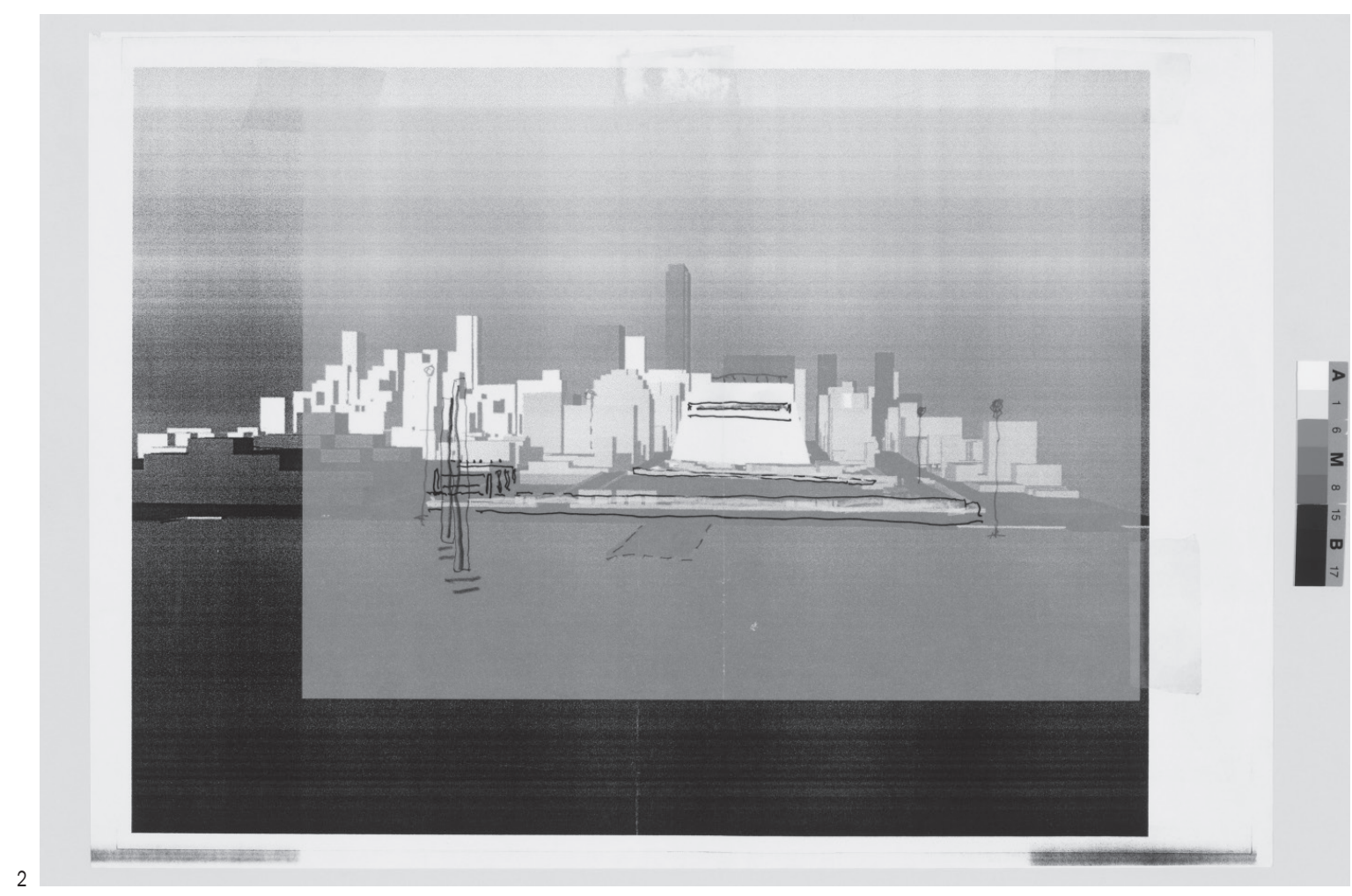

indudable valor pedagógico en un momento en que diferentes agentes promotores -públicos o privados- buscaban una arquitectura icónica, espectacular y de firma para atraer capital financiero. Sin embargo, es contradictoria, pues deja incuestionado el núcleo de lo que estos proyectos invitaban a reconsiderar: la identificación entre "espectacularidad", "producto inmobiliario", "desarrollo" y "bienestar". Este artículo profundiza en los valores de estos proyectos oscurecidos por esta lectura, y que tienen que ver con la atención sensible y el trabajo reflexivo sobre variables cualitativas existentes y apenas perceptibles. La idea de un "no hacer nada", hacer menos, no intervenir o economizar medios resulta insuficiente, a nuestro entender, para dar cuenta de ello, porque asume que que "hacer arquitectura" no es más que "construir", una premisa que dificulta la comprensión de estas estrategias y limita, consecuentemente, sus posibilidades de aplicación y desarrollo.

Para aclarar estas cuestiones, analizaremos la Escuela de Administración de Empresas de Burdeos de Lacaton \& Vassal (2006), en la que la atención a los aspectos cualitativos no está reñida con el construir. Al igual que los casos anteriores, se interviene en un contexto construido con el que se establecen nuevas relaciones sensibles a valores existentes. Veremos, además, cómo la codificación al uso en la mediación de la arquitectura especializada, así el tipo de planimetría, fotografía o narrativa, es refractaria en relación con este enfoque ${ }^{10}$. Para ello, iremos contrastando los significados promovidos desde diversos tipos de mediaciones culturales: publicaciones especializadas dirigidas a arquitectos y otras a un público no experto; las construidas por los propios arquitectos; la

10. La evolución editorial de una revista de gran impacto como El Croquis muestra cómo los protocolos editoriales al uso en revistas impresas de gran tirada y las grandes plataformas digitales están diseñados para dar soporte a la iconicidad. 


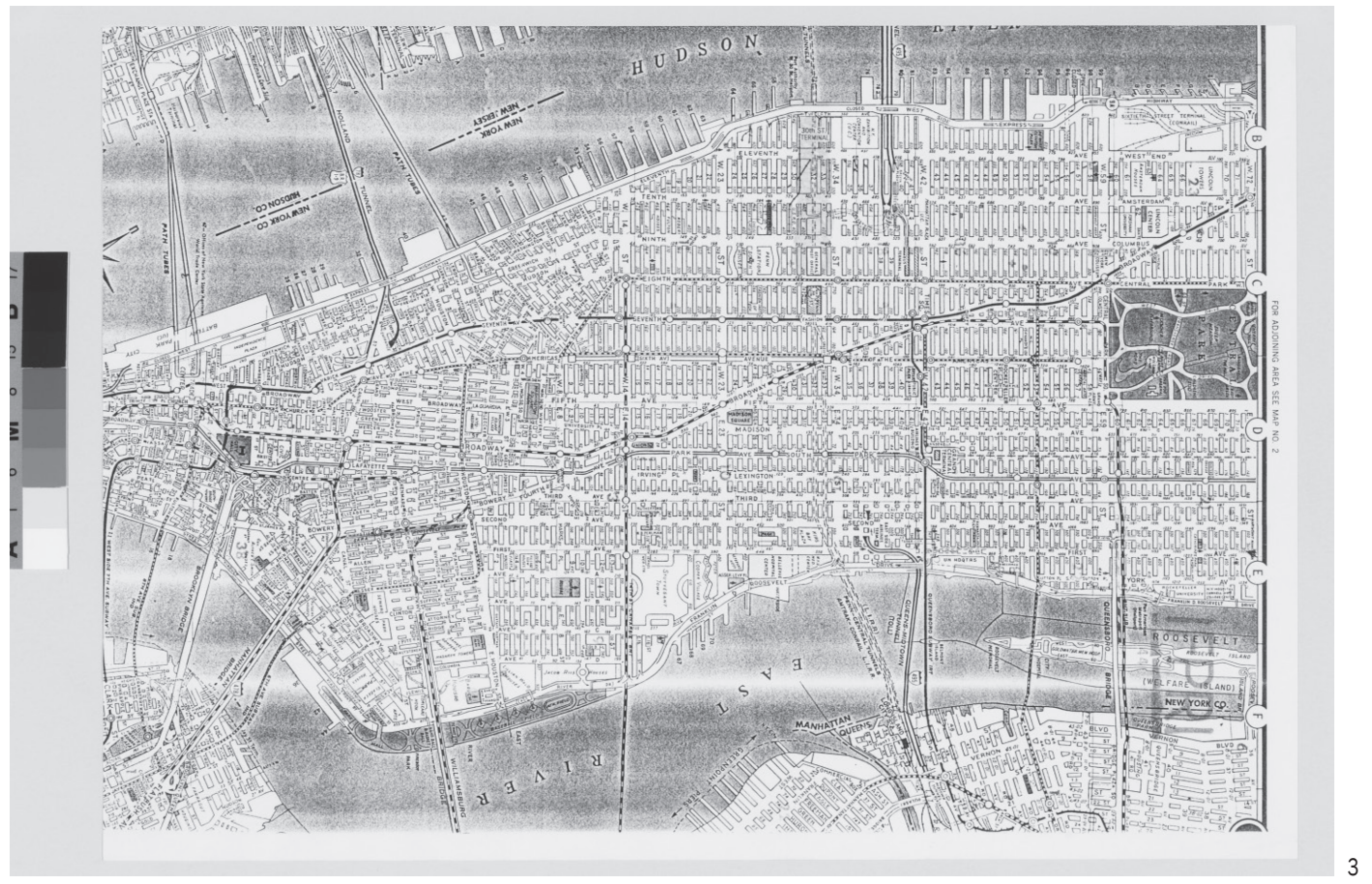

fotografía de arquitectura e incluso "imágenes pobres"11, como las tomadas por Google Street View o las subidas por usuarios a Google Maps. Nos interesan por estar alejadas de las codificaciones estéticas asumidas en la mediación especializada, que tienden a desconectar de lo mundano y lo cotidiano, de la experiencia vivida del entorno construido. Todo ello nos llevará a plantear la búsqueda de una "ecología de lo invisible", tanto en los proyectos edilicios como en la intervención urbana, como enfoque alternativo a la no-intervención, desde el que amplificar el alcance e ingenio de las técnicas de arquitectura.

UN PULMÓN PARA MANHATTAN, CEDRIC PRICE, 1998. VALORAR LO EXISTENTE Y RESCATAR LO OLVIDADO En 1998 Price cumple 64 años. A lo largo de su trayectoria no ha cesado en su empeño por reivindicar "la importancia de aquello que ha sido ignorado o rechazado". Uno de estos aspectos es el contexto: al tomarlo como materia prima, y no mero fondo para la nueva edificación, lo dignifica. Trabajando como "editor" del paisaje urbano,
Price había desafiado el imaginario asentado en torno al arquitecto como ingeniero y artista, genio inventor y autor individual $^{12}$. En Manhattan promueve una transformación semántica de las técnicas. Piensa que lo que la ciudad se está jugando no se resuelve únicamente en los hechos materiales y la experiencia, sino también en las superficies simbólicas que inundan nuestra cotidianidad, dando forma a una particular cultura que promueve determinadas formas de comprensión, relación y disfrute e inhibe otras. En este sentido, el artículo de Muschamp para The New York Times es el documento más completo de la escasa bibliografía sobre este proyecto. Mientras otros llegan taxativamente a la conclusión de estar ante un "no-hacernada", el periodista registra una multitud de acciones concretas: "El 'pulmón' del Sr. Price trata esencialmente el lugar como si fuera una reserva natural rectangular. Las vías del tren permanecerían descubiertas. Todo nuevo desarrollo estaría prohibido. Con el tiempo, algunos edificios existentes serían eliminados. El sitio estaría marcado con una cubierta brillante compuesta de pequeñas esferas de vidrio. Los límites este y oeste estarían equipados con es-

11. Como documento cultural, responden a lo que Hito Steyerl llama "imágenes pobres": descartadas de la circulación comercial por la mala calidad y la resolución por debajo de los estándares, son valiosas como herramientas cognitivas, porque tratan de las condiciones reales de existencia, y así hacen posibles movimientos de concienciación y afecto. STEYERL, Hito; BERARDI, Franco. Los condenados de la pantalla. Caja Negra, 2014, pp. 33-68.

12. Destacar como antecedente la carpa desmontable para 1200 espectadores, que tendría que ser montada en tres meses, para el Teatro Hair (1969). Situada entre un canal y un estadio, puede servirse de la iluminación, el control de acceso y el aparcamiento existente y usar los barcos del canal como camerinos; recupera, además, los asientos de un cine demolido de Birmingham y la estructura de acero de los desechos de construcción amontonados en un solar cercano. Este proyecto se puede consultar online en https://www.cca.qc.ca/en/archives/380477/cedric-price-fonds/396839/projects/407758/hair-tent 
3. Cedric Price. A Lung for Midtown Manhattan, 1998. Mapa de Manhattan con el enclave del concurso del Premio IFCCA para el Diseño de Ciudades y otros lugares destacados. Fotocopia en papel con detalles resaltados a lápiz de color, 29,7 × $21 \mathrm{~cm}$. Cedric Price fonds. Canadian Centre for Architecture.

4. Cedric Price. A Lung for Midtown Manhattan, 1998. Esbozo del plano de la localización del concurso destacando su posición en relación con la estación Grand Central, la New School y la Universidad de Nueva York. Tinta sobre papel, $29,5 \times 21 \mathrm{~cm}$. Cedric Price fonds. Canadian Centre for Architecture.

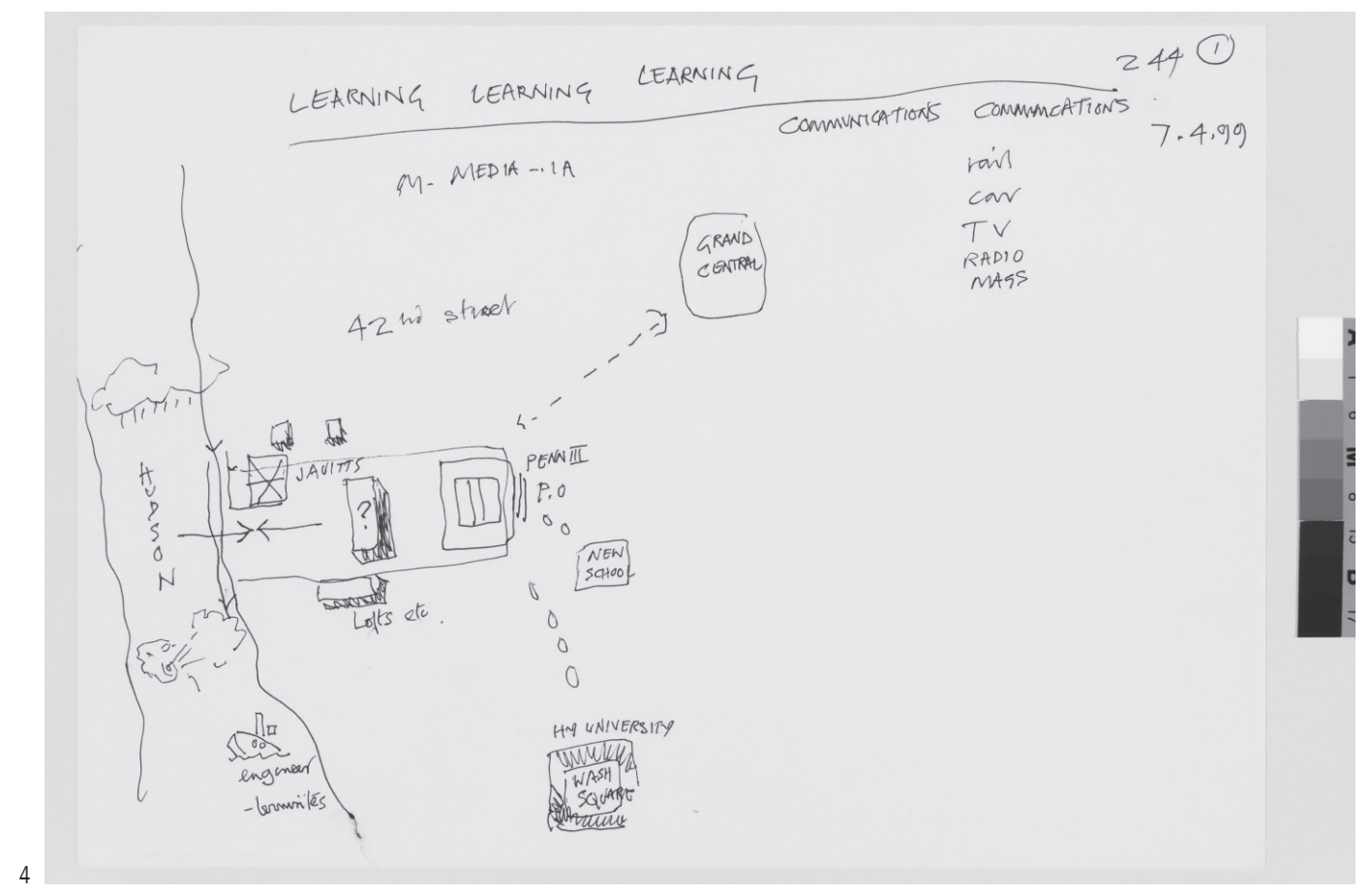

tructuras tipo túnel que el Sr. Price llama 'mangas'. Estas serían lugares donde la gente podría ir, sea cual fueren las condiciones climáticas, para contemplar las vistas de la ciudad y el río. También canalizarían el aire del río hacia el corazón de la ciudad. Se crearía un tercer puesto de observación cortando dos pisos de un edificio existente que se extiende a ambos lados de las vías"13.

Más que "no hacer nada" o "hacer menos", opta por preservar y poner en valor, a través de múltiples y pequeñas acciones, sus características más sobresalientes y desestimadas, de modo que sean ellas las que amplificaban a la arquitectura, y no al contrario. Desmenuza el proyecto en una mirada de pequeñas medidas atentas a las muchas y complejas variables que se escondían tras lo que el enunciado denominaba "vacío urbano" (figuras 2, 3 y 4). Price decide dejar el espacio "abierto", pero no "vacío". Propone construir un paseo elevado de sección tubular destinado a enmarcar vistas de forma selectiva colocando diversas cabinas elevadas. Incluye instrucciones para el movimiento de tierras o los patrones de escorrentía y drenaje del solar y acciones simbólicas junto a las infraestructuras que las permiten, como la torre desde la que se marcan con láser las aristas del volumen virtual de la "edificación perdida" por los promotores inmobiliarios y se retransmiten en tiempo real las condiciones de humedad y temperatura. Las vistas, el aire fresco o las mismas vías de tren -su cualidad narrativa como memoria del lugar y su carácter indefinido y "en barbecho"- son aspectos cualitativos que conservar y valorar. Dar visibilidad a estas variables insignificantes, desvelándolas como únicas e irrepetibles, restablece un equilibrio experiencial y simbólico que atañe no solo a lo concreto del lugar, sino a la cultura global como contexto en el que se pasan por alto. Además de una "reserva natural", se 
5. La ciudad enmarcada en el paseo urbano elevado a través las "mangas". Collage de lápiz y fotografías. Cedric Price, A Lung for Midtown Manhattan, 1998. Cedric Price fonds. Canadian Centre for Architecture. 6. Claes Johnson Visscher. Perfil de Ámsterdam, 1611. La palabra suple lo que la perspectiva oculta y lo que el dibujo no puede capturar.

ofrece una "reserva de distancia crítica", un arsenal imaginativo con el que llama la atención sobre "el papel sofisticado que los elementos anecdóticos y supuestamente prescindibles pueden llegar a desempeñar dentro del entorno y el paisaje contemporáneo", si los convertimos en el foco del proyecto arquitectónico, a través de una selección precisa ${ }^{14}$. En vez de una economía de medios, encontramos una "ecología de lo invisible".

En la monografía que a Price dedica Hans Ulrich Obrist en 2003, Arata Isozaki recuerda las palabras que durante las deliberaciones le dirigió el también miembro del jurado Philip Johnson: "Usted propondría sin duda a Cedric Price, y estoy de acuerdo, pero si su propuesta resulta la ganadora, el concurso perdería toda su relevancia social. iEs lamentable!" 15. Para el comisario de las míticas Modern Architecture (1932) y Deconstructivist Architecture (1988), la relevancia social del concurso radica en su capacidad para confirmar la idoneidad de una determinada imagen de la arquitectura, símbolo de un modo de práctica y una apariencia que cultivar. Para hacer espacio a otras posibilidades, Price tiene que desmontarla, como muestran los paneles presentados al concurso, una suerte de cruce entre el manual de instrucciones y el manifiesto. El texto predomina sobre los dibujos, esquemáticos y en miniatura, en el estilo gráfico escueto y directo que lo caracteriza. Numerosos fotomontajes y dibujos preparatorios, documentos de trabajo más que persuasivos, expresan el interés no solo por la singularidad del solar, sino también por las relaciones con la ciudad (figuras 2, 3, 4 y 5). Sobre ellos, Muschamp escribe: "El estilo único y distintivo del Sr. Price se extiende a su modo de presentación. En lugar de los glamurosos renders utilizados por los otros concursantes, ofrece ásperos bocetos a lápiz que parecen haber sido apresuradamente trazados en servilletas entre sorbos de clarete. Incluso el término 'mangas' evoca una informalidad extrema: la confección personalizada de un refinamiento tan exquisito que hace que una chaqueta parezca completamente informe. Sin embargo, lo cierto es que este diseño es realmente el único de los cinco que va más allá de las cualidades formales de la arquitectura para abordar la calidad de la vida urbana. La principal preocupación del Sr. Price es, dicho en términos muy sencillos, la salud pública. Su objetivo es mejorar el aire, la cantidad de luz disponible y la liberación psicológica que proporciona el espacio abierto. Es, en efecto, un parque en el que la arqueología de la ciudad industrial toma el lugar del paisaje bucólico"16.

La metodología proyectual y los esquemáticos dibujos de Price ciertamente desafiaban la imagen de la arquitectura que Johnson había ayudado a forjar. Modern Architecture, su catálogo y el subsiguiente libro The International Style (1932), sentaron las bases para los actuales protocolos de mediación de la arquitectura, en contraste con la intensa exploración editorial de los mismos arquitectos expuestos ${ }^{17}$. Estos protocolos se basan en la separación de texto e imagen y su aislamiento como fenómeno estético a través de la "fotografía de producto", estilo comercial basado en el punto de vista frontal y centrado en la figura, un encuadre ajustado para eliminar el contexto, la preferencia por la luz diurna y diáfana, la ausencia de referencia a la vida, el trabajo y las tribulaciones $\operatorname{cotidianas}^{18}$. El aislamiento de la fotografía en la página reproduce el efecto de enmarcado característico de los museos estatales modernos, concebidos como

14. Sobre este enunciado, ver WIGLEY, Mark. Towards a History of Quantity. En: Ole BOUMAN; Rem KOOLHAAS; Mark WIGLEY, eds. Volume 2: doing (almost) nothing. Ámsterdam: Archis, 2005.

15. ISOZAKI, Arata. Erasing architecture into the system. En PRICE, C., op. cit. supra, nota 8, p. 46.

16. MUSCHAMP, Herbert, op. cit. supra, nota 3.

17. Ver ÁLVAREZ, Paula V. Un territorio común, casi olvidado. En: Francisco GONZÁLEZ DE CANALES, El manierismo y su ahora. Una aproximación optimista para un presente incierto. Sevilla: Vibok Works, 2020, pp. 72-103.

18. Surge a comienzos del siglo XX como estilo comercial para los catálogos de venta a distancia. Sobre las bases estéticas e ideológicas de la fotografía publicitaria, ver CORONADO, Diego. De la publicación de la fotografía a la fotografía publicada en torno a los orígenes decimonónicos de la fotografía publicitaria. En: Ámbitos. Revista Internacional de Comunicación, 2000, n. 3-4, pp. 221-245. En su crítica a la fotografía especializada de arquitectura, Fredric Jameson afirmaba que eran imágenes falsas construidas para presentarla inflexiblemente como mercancía autónoma, sujeta a un proceso de comodificación. JAMESON, Fredric. Spatial Equivalents in the World System. En: Postmodernism, or the Cultural Logic of Late Capitalism, Londres: Verso, 1991, pp. 97-129. 

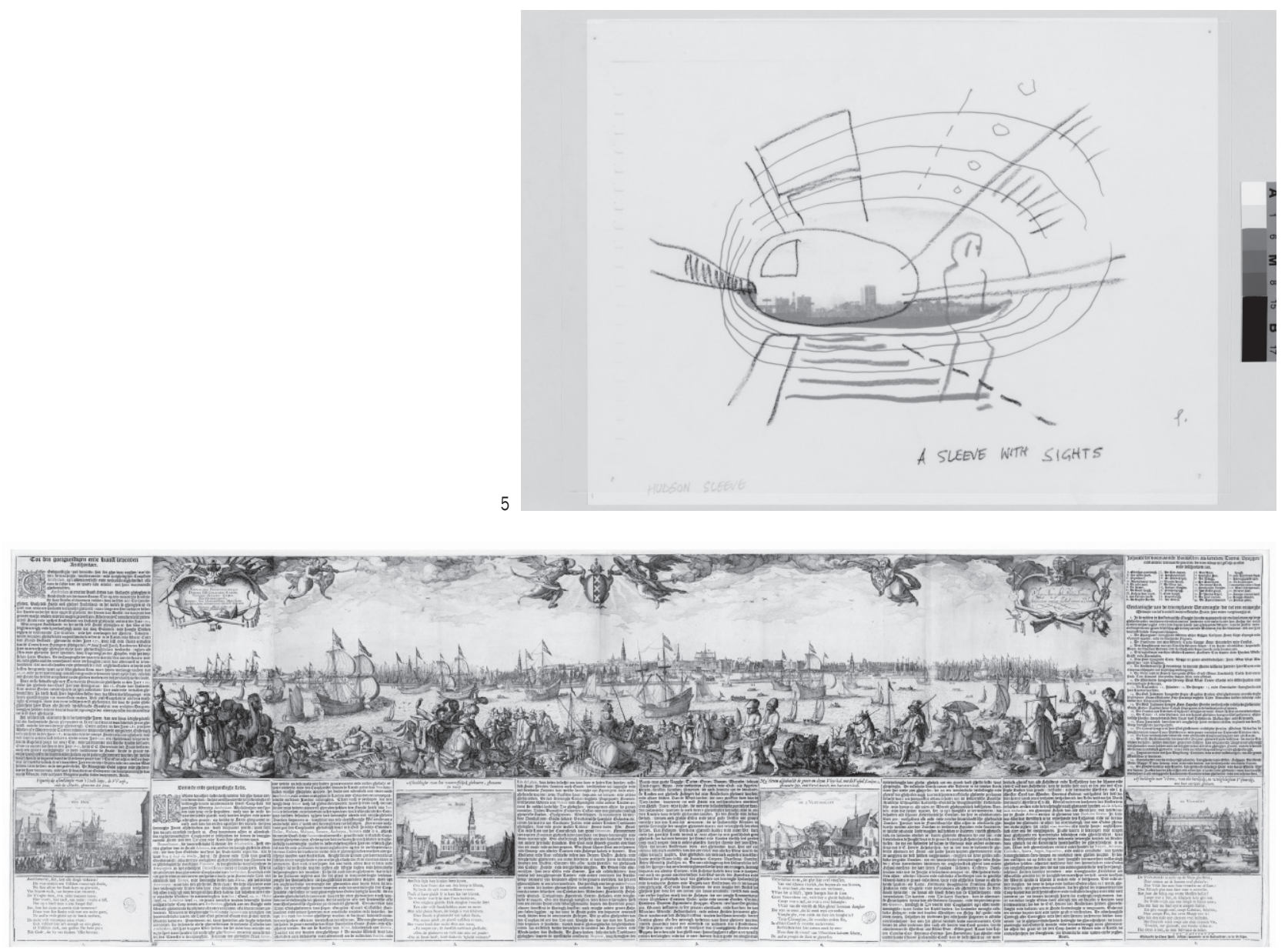

aisladores de fenómenos para generar un aura de solemnidad y prestigio alrededor del objeto artístico ${ }^{19}$. Invirtiendo las jerarquías que dan soporte al régimen de lo valioso útil a los flujos económicos, en vez de enmarcar el objeto arquitectónico en sus paneles, Price enmarca las vistas del entorno (figura 5).

Nótese la diferencia entre la reproducción inmersiva de la experiencia del habitante en la única "vista" de Price (figura 4) y los renders a vista de pájaro de Eisenman (figura 1). Price confronta el render como herramienta financiera y la fotografía de producto, que tienden a escindir los edificios de las circunstancias materiales y sociales de su desarrollo. En su alejamiento consciente del consenso tácito de representación, expone e interroga la lógica de la mediación y del propio concurso ${ }^{20}$. Los paneles recuerdan un tipo singular de representación cartográfica de perfiles urbanos del siglo XVII, en los que las descripciones textuales suplían aquellos aspectos ocultados a la visión por las perspectivas enlazadas de múltiples puntos de vista a la altura del ojo humano (figura 6). Price utiliza el texto para dar visibilidad a todo aquello que los estilos y las normas de representación y narración hegemónicas impiden advertir. Los paneles son un inventario de pistas ínfimas que confrontan a la imaginación arquitectónica con aquello de lo que estaba siendo fortuitamente desconectada. Entre lo crítico y lo propositivo, la intervención misma se concibe como herramienta educativa que, haciendo justicia a lo olvidado, lo relanza como punto de partida.

19. Sobre el museo como aislador de fenómenos, ver el capítulo “Insularizaciones” de SLOTERDIJK, Peter. Esferas III. Madrid: Siruela, 2014.

20. "Ninguno de los proyectos está oficialmente autorizado. Ninguno tiene clientes. [...] El Sr. Price eligió no estar de acuerdo con la suplantación. Ninguna nueva construcción masiva. No hay estadios deportivos. Sin crujidos de huesos urbanos. Sin calistenia estructural de alta tecnología. No hay que hacer heno. Solo una ligera capa de vidrio glaseado y una brisa que sopla desde el río. Solo un lugar para que una ciudad respire". MUSCHAMP, Herbert, op. cit. supra, nota 3. Davide T. Ferrando reflexiona sobre el uso del render glamuroso en las estrategias de marketing que parten de la arquitectura como puro instrumento financiero. FERRANDO, Davide T. La ciudad en la imagen. Sevilla: Vibok Works, 2018, pp. 193-236. 


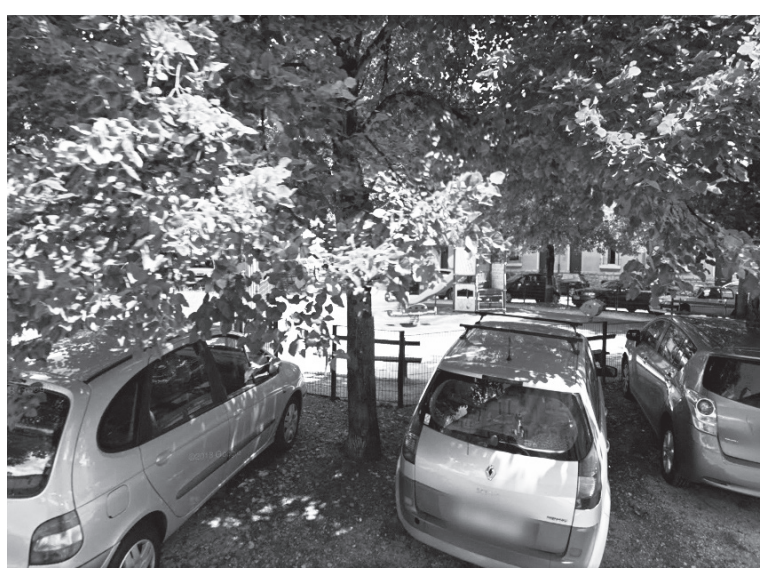

$8 \mathrm{a}$

relevante de ambas es el rescate de lo olvidado y lo pasado por alto, de aspectos insignificantes y livianos, apenas perceptibles, que todos consideraron suplemento prescindible menos los arquitectos, incluso cuando su fuerza resulte ilegítima e infundadamente arquitectónica.

Robin Wilson ha llamado la atención sobre la forma aséptica en la que una propuesta tan singular como Léon Aucoc se aborda en la mediación especializada ${ }^{27}$. El impacto del discurso crítico de la oficina se diluye al adoptar las normas de presentación fijadas en el monográfico que $2 \mathrm{G}$ le dedica en 2002, pero diversas incongruencias desvelan que algo ha sido reprimido. La primera es el uso insistente de la palabra "nosotros" en la descripción de este proyecto, rompiendo con la despersonalización descriptiva de los otros 16 proyectos publicados. La segunda está en las dos fotografías de la plaza, probablemente tomadas por los arquitectos en una visita a obra, y maquetadas de forma similar a las que el fotógrafo Philippe Ruault toma de los otros proyectos. La tercera se refiere a la fecha de construcción, que indica 1996. Pese a la insistencia en que la plaza "es bella como está", se incide en que hay "algo" realizado que no es edificación. Estas incongruencias muestran el conflicto entre el reconocimiento del trabajo intelectual y el rechazo de la estrategia en el nivel institucional del discurso editorial, expresado a través de un formato de presentación que lo es también de regulación, pues excluye e incluye, nos instruye sobre

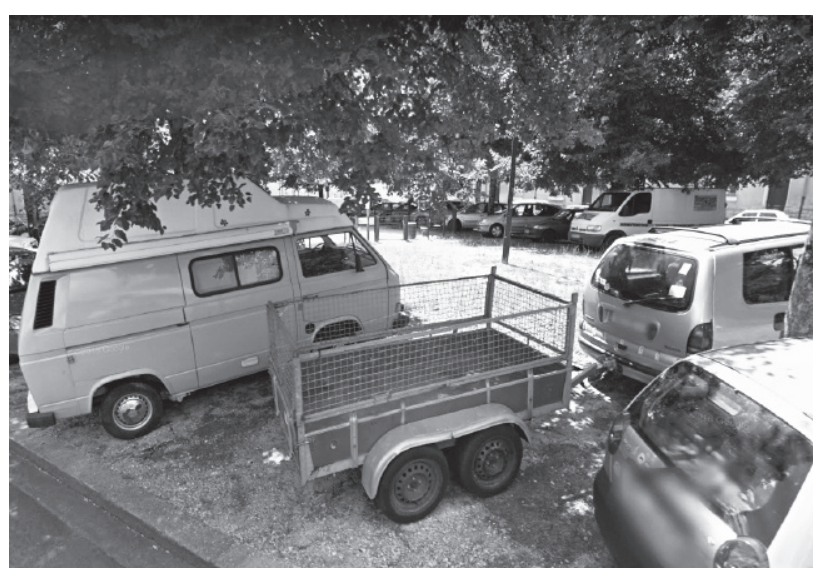

$8 b$

lo valioso y lo correcto ${ }^{28}$. Wilson no comenta, porque posiblemente lo desconoce, una incongruencia mayor: la supresión consciente y consensuada en la descripción del proyecto de la producción de un "catálogo de recomendaciones" que incluye una cuestión política, como es levantar la prohibición a las hogueras de San Juan.

Acudiendo a Google Street View como documento cultural no orientado por los intereses que subyacen a la mediación especializada de la arquitectura, encontramos una realidad bien distinta a la que muestran aquellas fotografías de 1996. Los vehículos han invadido el solar, convertido en aparcamiento (figura 8). La superficie destinada a uso público se limita a un mínimo reducto apoyado en el lado menor de la plaza: un tobogán rodeado de bancos y alambrado como un solar privado, posiblemente una medida económica de urgencia para protegerlo de la invasión de vehículos. ¿Qué hubiera pasado si, cambiando el imaginario social de la plaza, se hubieran permitido actividades arraigadas popularmente como las hogueras de San Juan? ¿Y si en vez de idealizar el no intervenir se hubiera rediseñado la vegetación, el mobiliario o el pavimento para regular los tránsitos y preservar su carácter de espacio libre, público? Al igual que la realidad congelada de la experiencia de la visita a obra, elegida para representar una versión simplificada y apaciguadora del proyecto, la no-intervención es también una incongruencia que expone los límites a los que la imaginación

27. WILSON, Robin. Evidence of "Doing Nothing”: The Utopic Document of Lacaton \& Vassal. En: Architectural Theory Review, 2013, vol. 18, n. ${ }^{\circ}$ 1, pp. 30-45, p. 32. Wilson afirma que la acreditación sistemática de los fotógrafos de arquitectura denota "que el edificio ha sido presenciado por un iniciado en el canon, como si fuera un acto final que lo certificarse como producto perfectamente adecuado para su difusión mundial". Este canon perpetúa normas genéricas que reducen ampliamente el alcance de la fotografía como agente activo en la interpretación de la arquitectura. Su análisis parte de JAMESON, Fredric. The Political Unconscious: Narrative as a Socially Symbolic Act. Londres: Routledge, 1983, donde urge a buscar evidencias de impulso utópico en las formas culturales del capitalismo tardío ante el "cierre sistémico, cultural e ideológico" de nuestro sistema actual.

28. Para Wilson, la neutralidad de los textos, de estilo descriptivo y despersonalizado "reflejan ampliamente, o intentan asumir, la supuesta posición de las ilustraciones de los proyectos, que, en el caso de los proyectos completados, toman la forma de fotografías de gran formato producidas profesionalmente, es decir, intentan proporcionar un retrato 'objetivo' y 'neutral'. WILSON, íbid., p. 36. 


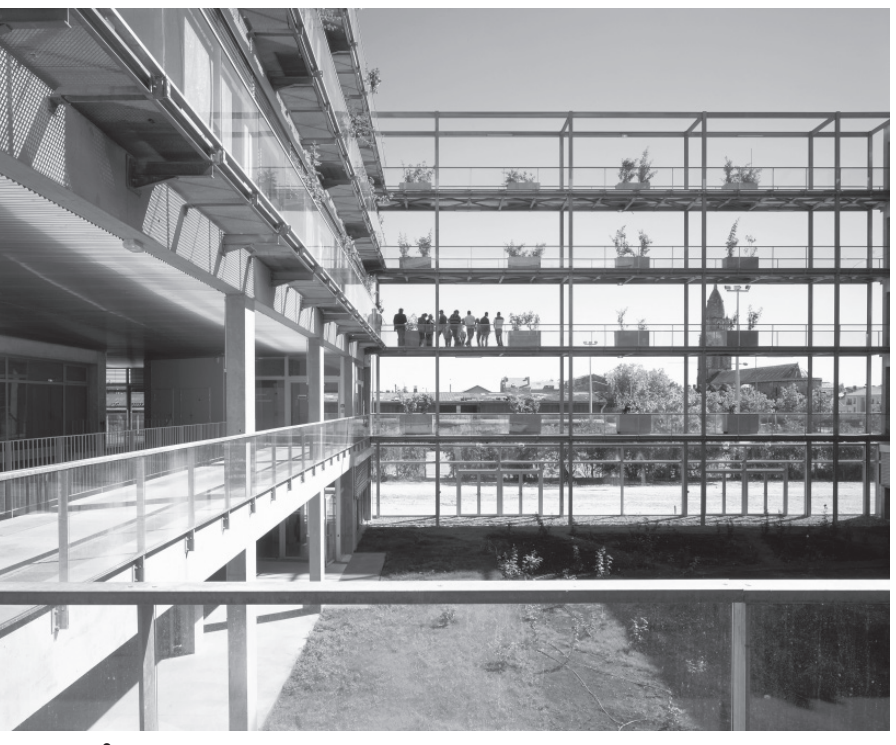

9

proyectual podría resistirse: la arquitectura no es un fenómeno aislado, sino un sistema de elecciones que nunca resulta, incluso si se elige no hacer, en una imagen congelada. Más que "revelar y mantener lo existente", el reto hubiera sido "canalizar los valores desestimados" hacia la experiencia vivida y las superficies visibles.

\section{LA ESCUELA DE ADMINISTRACIÓN DE EMPRESAS, LACATON \& VASSAL, 2006. DE LA ATENCIÓN SENSIBLE A LO EXISTENTE A LA EDICIÓN DE LA ARQUITECTURA}

La transformación cualitativa del hábitat no radica estrictamente en la construcción, pero tampoco está reñida con ella. Así sucede en la Escuela de Administración de Empresas (2006), proyectada por Lacaton \& Vassal una década después. La presencia y el aroma de delicados rosales en los patios traseros de las modestas viviendas de trabajadores colindantes con el solar inspiraron su emblemática envolvente. En la conversación antes referida con Ruby, Vassal afirma: "[...] el proyecto trabaja absolutamente en relación con su contexto al prolongar e integrar un aspecto esencial de su realidad material: los jardines. La zona residencial, como ves, está formada por pequeñas viviendas adosadas para trabajadores, que datan del s. XIX. Todas tienen jardines que informan
9. Escuela de Administración de Empresas de Burdeos; la presencia del edificio simbólico y el perfil urbano se percibe desde el patio a través de la fachada desmaterializada. Fotografía de Philippe Ruault.

10. Muestra de la web del proyecto con el reportaje fotográfico de Philippe Ruault.

el carácter del barrio, al menos tanto como las mismas casas. Interesados por esta cualidad vegetal del espacio, nos dimos cuenta de que había una gran cantidad de árboles rosales en los jardines. Consecuentemente, decidimos 'floralizar' el edificio para la universidad también, colocando 600 rosales diferentes en espacios exteriores como la galería y los patios interiores. Es importante notar que estos árboles no son solo decorativos, sino también performativos. Desde que el edificio fue inaugurado en 2006, las personas que trabajaban en la universidad junto con los habitantes del área residencial del barrio se han unido y han comenzado a cultivar las rosas, iy ahora incluso producen una mermelada de las hojas de las rosas!"29.

Si Lacaton \& Vassal rescataban en Léon Aucoc la cultura popular expulsada al instar a la Administración local a que levantara la prohibición de las hogueras, aquí el acontecimiento ordinario ligado al habitar transforma a la edificación. La epidermis urbana se engrosa para evocar la singularidad del enclave, la diferencia cultural, la movilización cotidiana de los sentidos y los afectos (figura 9). El valor profundo de la obra de Lacaton \& Vassal no está en su estética povera o su adscripción al no-hacer. Al igual que el trabajo de Price, se inscribe en el universo de lo cualitativo, en el que la belleza, la utilidad y el placer no pueden medirse con dinero. El aspecto invisible que rescata se refiere a un bienestar psicológico que se ha convertido en un lujo, algo a lo que es difícil de acceder no por su coste, sino porque es difícil de ver y apreciar.

La edición oficial de esta obra da cuenta de ello: en una forma de autocensura, editores, autores, críticos y fotógrafos prefieren diluir estos aspectos. Tanto en la monografía como en la web del estudio se omite el origen de la solución de la fachada, presentándola de forma aséptica $^{30}$. El engrosamiento que equilibraba la inevitable distancia entre la técnica y la naturaleza, lo maquínico y la espontaneidad vital, se reduce a juego de contrastes: el detalle delicado de los rosales frente a la tersura de la técnica. El signo dionisiaco de las rosas se equipara y nivela con el poder apolíneo del cristal, avatar del discurso 

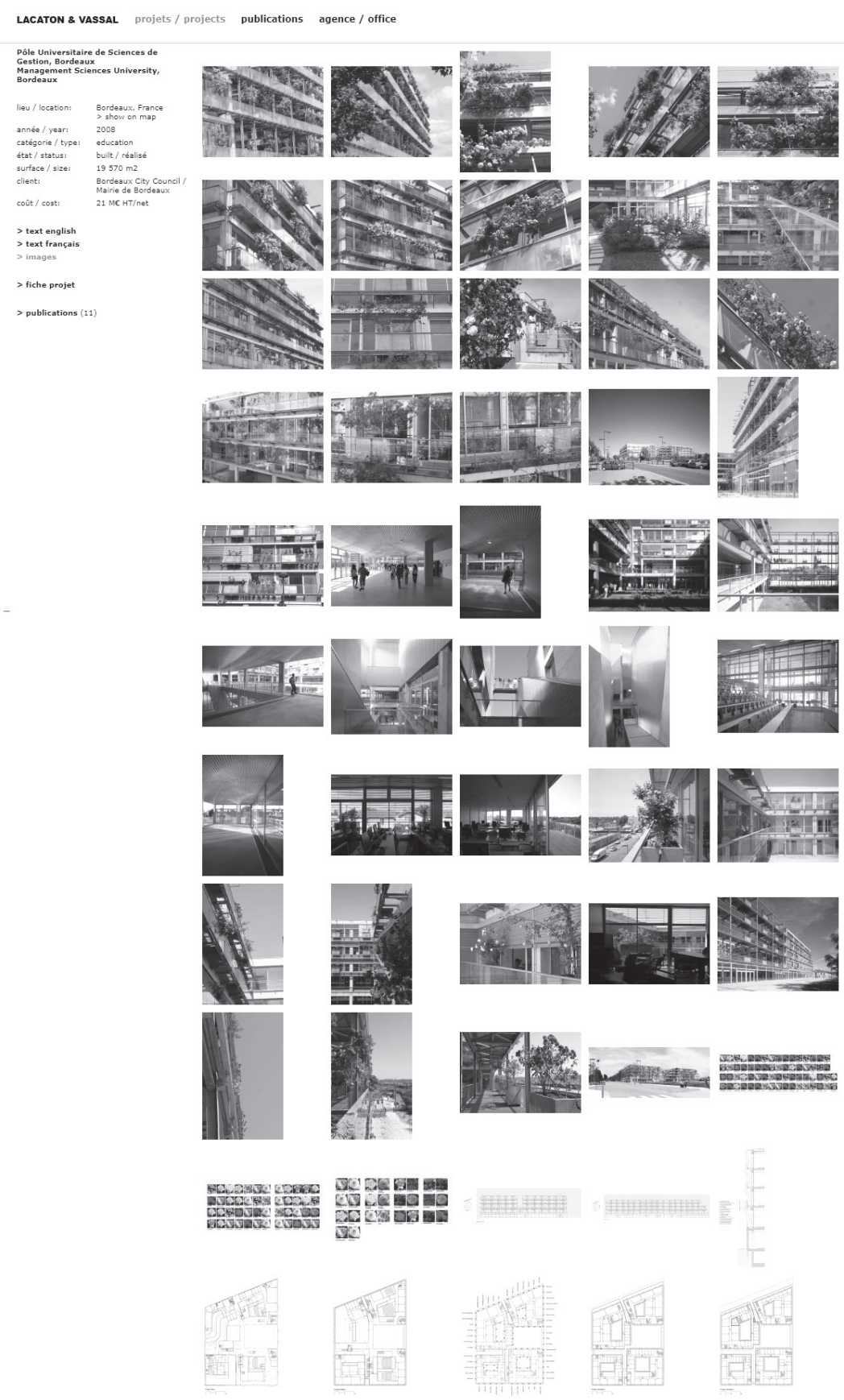

científico-técnico, de la Razón. Las relaciones humanas, corporales y afectivas desaparecen o se tornan pasivas.

Vassal afirma que la "trasfusión del contexto" a la arquitectura se origina en el deseo de acercarlo a la ciudad: un "nuevo contextualismo", lo llama Ruby. Los rosales representan un intento de superación de una condición refractaria de la que no logran desprenderse. Al reducir a naturalismo el nexo no refractario con el contexto, la mediación editorial cancela la posibilidad de otorgar complejidad a la apariencia, traicionando las promesas de una amplificación experimental del alcance de la arquitectura. El profuso reportaje de 44 fotografías que toma Ruault escenifica visualmente esta desconexión (figura 10). Dos pertenecen a la volumetría, 12 a los espacios interiores y 30 a la fachada. De estas últimas, 24 están tomadas o bien desde la cota cero, el nivel de acceso, dirigiendo la mirada hacia arriba desde un punto próximo a la fachada, o bien desde un punto elevado, de forma 


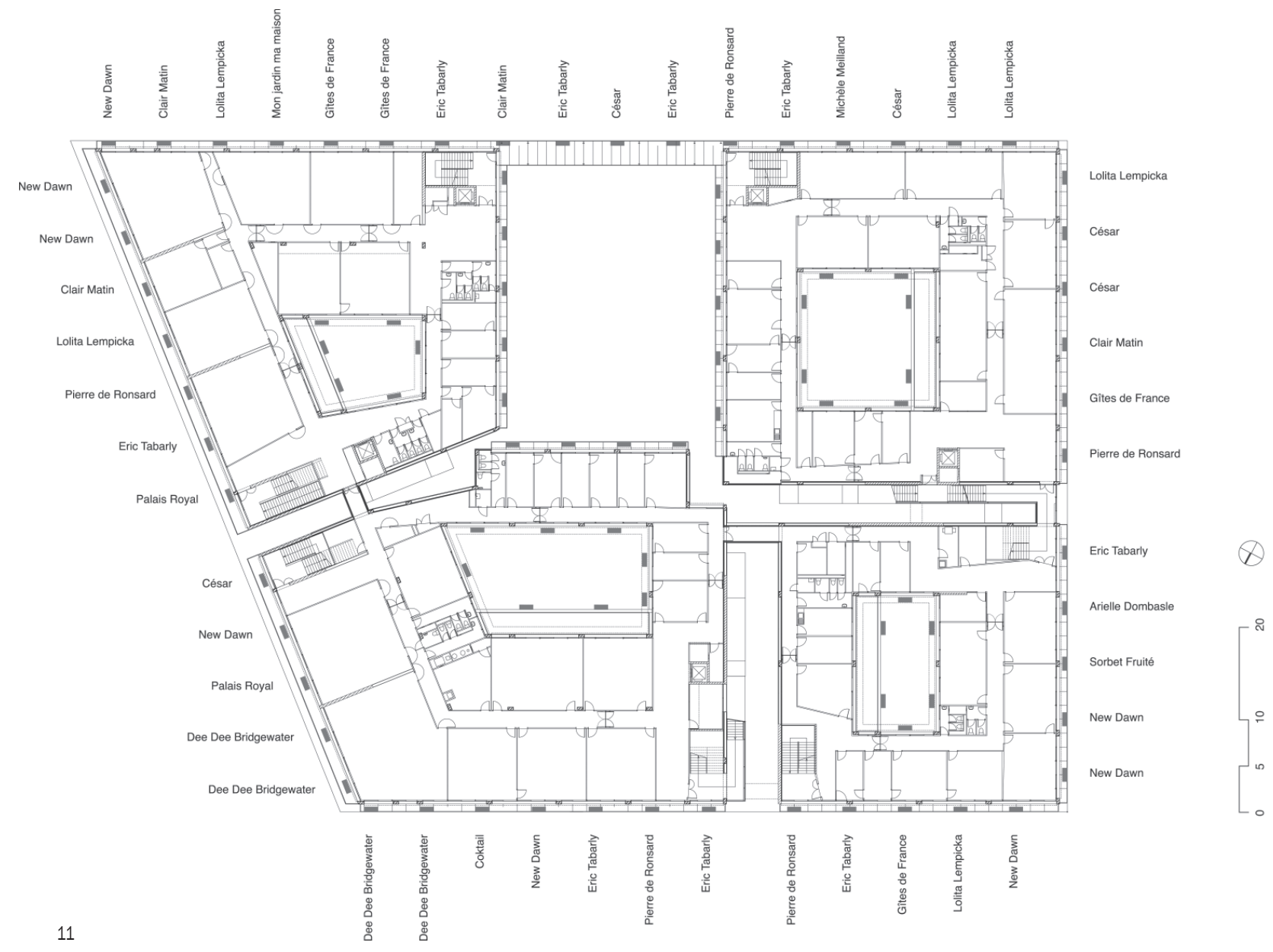

que la calle y el contexto quedan eliminados del "retrato" y del "relato". El cuidadoso encuadre enmarca detalles de las plantaciones de rosales, estetizando el motivo y saturando con él nuestra mirada. Los puntos de vista y los encuadres elegidos sustraen el edificio del entorno circundante, hasta el punto de diluir su presencia, solo reconocible como tal en dos de las 44 imágenes. Significativamente, estas están tomadas desde dos puntos de vista fuera del sistema de espacios libres: el patio y el callejón lateral cerrado al público. Parece que se quisiera eludir el contexto, también borrado de la planimetría. No hay un solo plano que muestre las calles circundantes y el pequeño barrio de casitas adosadas con jardines cuyos aromáticos rosales inspiraron la fachada que se ha convertido en "imagen" del trabajo de la oficina, elegida para la portada de dicha monografía ${ }^{31}$.

Tanto en las páginas de la monografía de 2G como en la propia web ${ }^{32}$, las plantas y secciones flotan, insularizadas (figura 11). Suprimida en la monografía y la web la relación erótica del edificio con los jardines del contexto, los usuarios y los vecinos, se elimina del relato colectivo como hallazgo pedagógico, sellando los límites

31. No es un episodio aislado. Varios autores han observado cómo la planimetría y fotografías utilizadas para representar el Seagram reducen la complejidad del encuentro con el entorno, favoreciendo la lectura del edificio como prisma opaco refractario al contexto. MIGUEL, Sergio de. Donde se rompen las nubes: Lever House, Nueva York 1950. Director: Javier Frechilla Camoiras. Tesis doctoral. ETS Arquitectura, UPM de Madrid, 2015. ALMONACID, Rodrigo. Mies van der Rohe ¿mal interpretado o mal publicado? El caso del Seagram. En: Veredes. Arquitectura y Divulgación [en línea]. 21 de mayo de 2018 [consulta: 30-09-2020]. Disponible en: https://veredes.es/blog/mies-van-der-rohe-mal-interpretado-mal-publicado-caso-del-seagram-rodrigo-almonacid/. Rosa Añón observa cómo la representación de la Bauhaus ha limitado la comprensión de "uno de sus valores principales: el control territorial que ejerce en el desarrollo urbano". AÑóNABAJAS, Rosa María. La Bauhaus, de Dessau a Ulm: ensayos sobre el espacio docente de alto rendimiento/The Bauhaus, from Dessau to Ulm: essays on this high yield educational space. En: Proyecto, Progreso, Arquitectura, 2010, n. ${ }^{1}$ 1, pp. 26-45, p. 27-29. D0I https://doi.org/10.12795/ppa.2010.i1.02

32. Lacaton \& Vassal [consulta 30-09-2020]. Disponible en: https://www.lacatonvassal.com/index.php?idp=10 
11. Muestra de la representación oficial de la Escuela de Administración de Empresas de Burdeos. El bloque se muestra exento y sin contexto, incluida la planta baja. Archivo Lacaton \& Vassal.

12. La relación de la Escuela de Administración de Empresas de Lacaton \& Vassal con el tejido inmediato a través de una vista aérea en Google Maps. 2018. 13. Calle lateral colindante con las viviendas para obreros. La Escuela de Administración de Empresas de Lacaton \& Vassal a través de Google Street View. 2018.

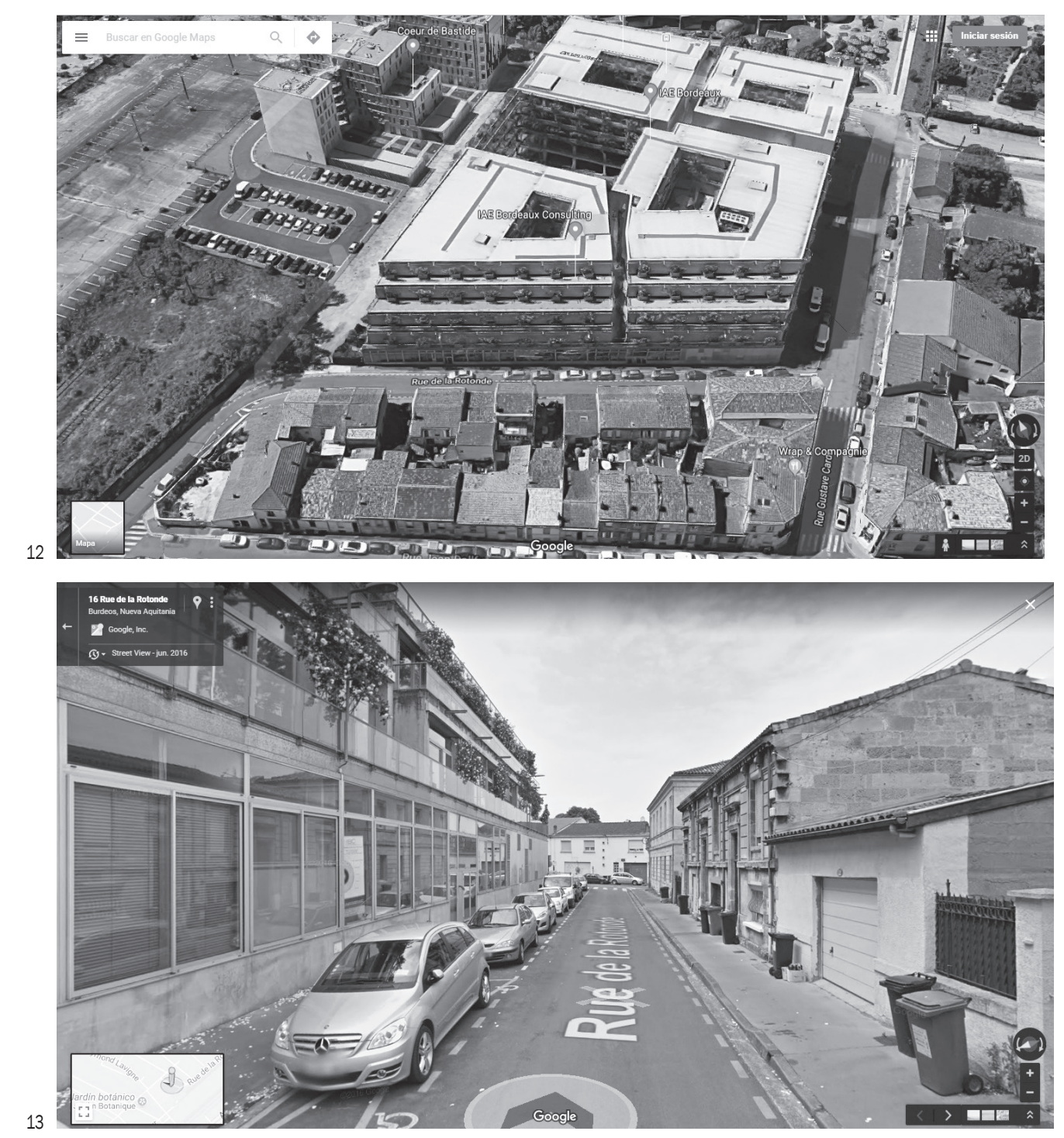

impuestos a la imaginación proyectual. De nuevo, Google Maps nos da acceso a un imaginario más crudo, pero más veraz y conectado con la experiencia vivida. A su través podemos sobrevolar los frondosos jardines del barrio de viviendas obreras adosadas adyacentes e intuir los rosales que embriagaron a los arquitectos (figura 12). Situando el visor a pie de calle, intuimos por qué la percepción del edificio en su entorno ha sido descartada en el reportaje fotográfico. Las casas de los trabajadores, de escala modesta, no tienen un especial interés visual y están algo deterioradas: una realidad que contrasta con los códigos estéticos de la fotografía de arquitectura.

En la planta baja, los cerramientos acristalados reflejan estas viviendas modestas, amortiguando con su presencia el impacto del volumen en el contexto. Hay en ello una componente poética, pese a los vehículos estacionados y los cubos de basura (figura 13). 


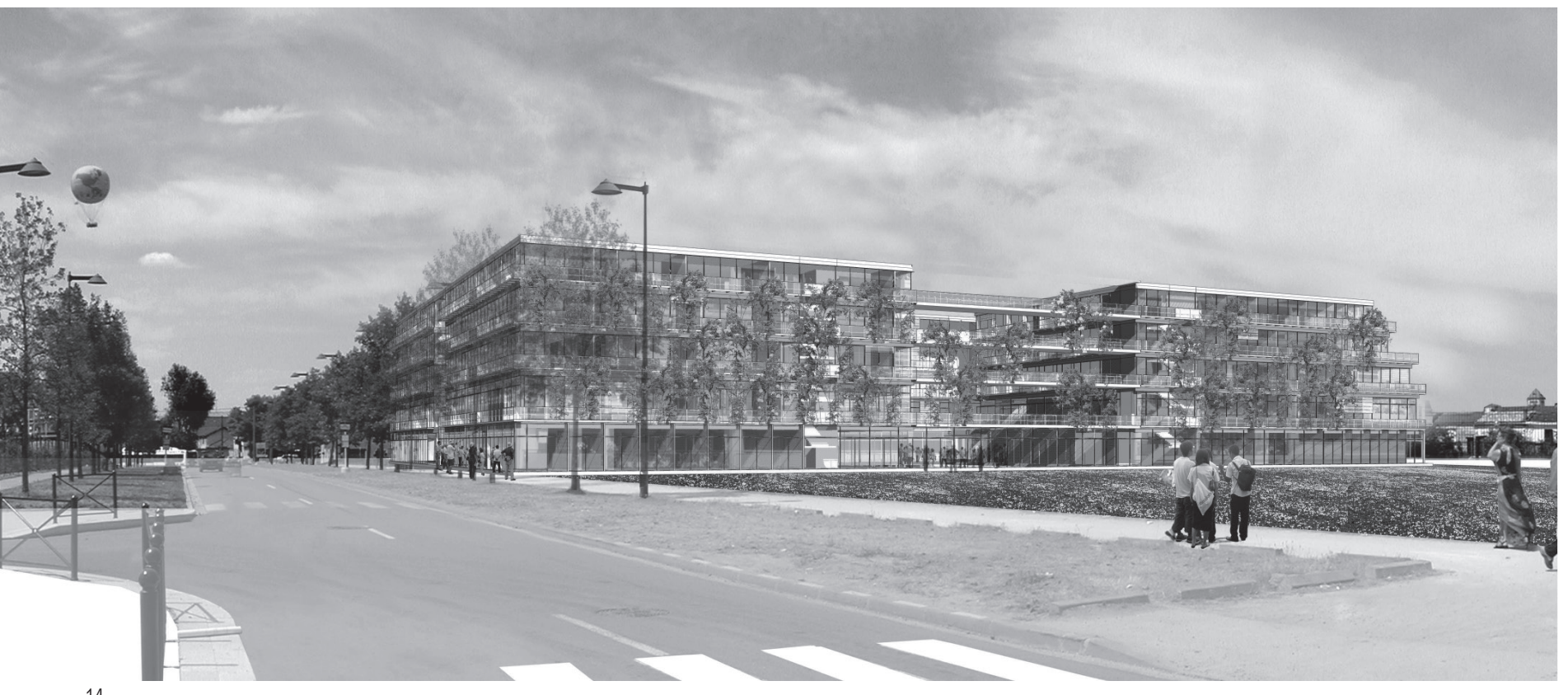

El reflejo del entorno en la fachada acristalada también se apercibe en las imágenes desidealizadas subidas por los usuarios ${ }^{33}$. Obtenemos acceso a aspectos vivenciales, culturales, sociales, ecológicos y antropológicos que Lacaton \& Vassal consiguen con el tratamiento de la fachada. Ese lujo que la edición nos niega. La presencia de los rosales es mucho más discreta de lo que el reportaje floral de Ruault, emulando al render previo a la construcción, quiere dar a entender (figura 14); pero no son por ello menos hermosas. Los códigos estéticos que rigen su mediación espectacularizan este detalle, glamurizando un edificio del que también podríamos decir que "ya es bello tal y como está".

Si la ciudad simbólica se introduce en el patio a través de las transparencias de la fachada desmaterializada (figura 9), aquí es la ciudad cotidiana la que empaña simbólicamente, por así decirlo, la arquitectura. Mientras la web del estudio y las revistas especializadas desmantelan tal intento de amplificar la arquitectura, en las calles de Burdeos, las fachadas de la Escuela de Administración de Empresas continúan contando una historia diferente (figura 15), más cálida y más honesta que su versión edulcorada.

\section{CONCLUSIONES. HACIA UNA ECOLOGÍA DE LO INVISIBLE}

Reconsiderar las técnicas proyectuales para mejorar cualitativamente el entorno construido puede tener como horizonte la búsqueda de una "ecología de lo invisible". Para defender este enfoque, alternativo a la no-intervención, nos hemos apoyado inicialmente en la lectura que hace Herbert Muschamp de la propuesta A Lung for Midtown Manhattan y la representación del propio Price, que desmenuza una serie de acciones concretas relacionadas con la atención a los valores del enclave la ciudad, explorando su capacidad para proporcionar disfrute y bien-

33. Erráticas y fortuitas, estas imágenes presentan el edificio en el contexto, confirmando que la estrategia proyectual difiere de lo publicado en el monográfico $2 G$ y la web de los arquitectos; abren, además, interrogantes acerca de la relación entre pobreza, visibilidad, lujo y vulgaridad. 
14. Render de la propuesta para la Escuela de Administración de Empresas de Lacaton \& Vassal. Archivo Lacaton \& Vassal, 2004.

15. El reflejo del entorno en la fachada transforma la presencia del edificio. La Escuela de Administración de Empresas de Lacaton \& Vassal a través de Google Street View. 2018.

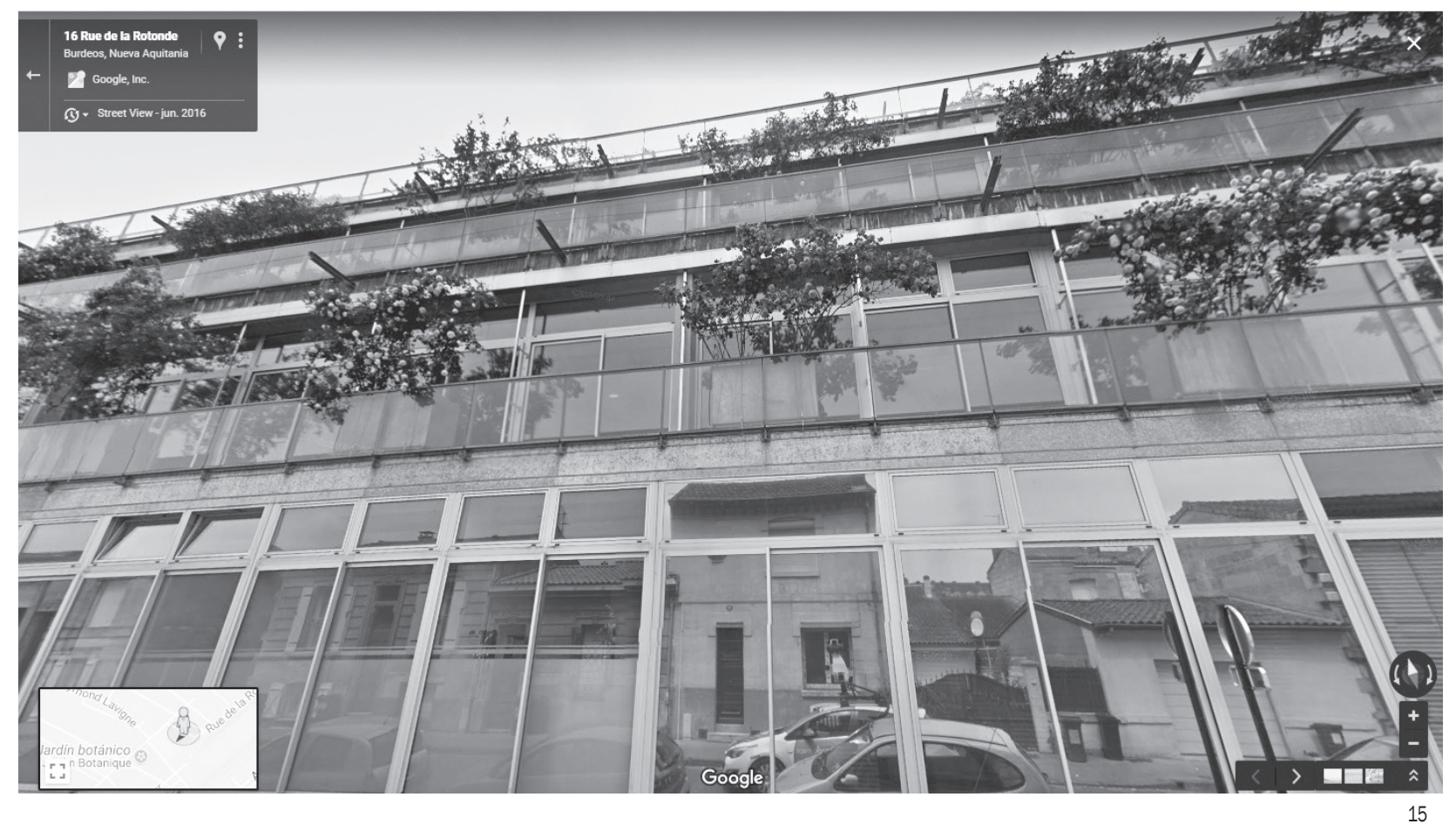

estar psicológico. Estos valores se refieren a aspectos cualitativos apenas perceptibles, como la sensación de amplitud espacial, las vistas o la brisa que atraviesa el solar, pero también a aspectos pragmáticos, como la proximidad de la universidad, y simbólicos, como la renuncia a colmatar el solar con construcciones. Este último aspecto es la base de las interpretaciones (no-intervención, economía de medios, antiarquitectura...) que tratamos de reevaluar, pues pueden llegar a oscurecer la comprensión de aspectos cruciales del trabajo proyectual como despliegue sensible de una atención crítica.

En el análisis de la plaza Léon Aucoc y la Facultad de Empresariales de Lacaton \& Vassal hemos ahondado en ambos aspectos, buscando cuáles serían esos valores implicados en la ecología de lo invisible y cómo son desplazados en los relatos y codificaciones especializadas al uso. Estos valores incluirían aspectos sensoriales, ambientales, culturales y antropológicos que contribuyen a cualificar simbólica y eróticamente cada enclave concreto. Hemos acudido a documentos culturales como
Google Street View, libres de la codificación editorial normativa, para mostrar cómo esta puede llegar a dificultar enormemente los procesos de transferencia de información, de savoir-faire, y el desarrollo de técnicas y de modelos alternativos. Los medios especializados, al desestimar la ecología de lo invisible, pueden desvalorizar la arquitectura, reduciéndola a la exhibición visual y técnica de sus componentes, indiferentes a las relaciones sutiles con el contexto social, cultural, geográfico y antropológico.

La "ecología de lo invisible", por tanto, comprendería la atención sensible al contexto y el lugar como entramado de fuerzas, material de trabajo y fuente de riqueza con los que establecer relaciones. Pero también un permanente rescate de lo oculto, lo invisible y lo olvidado -por los agentes promotores, los habitantes, la ciudad o la propia cultura arquitectónica- para que pueda ser acogido en la resolución conceptual, formal, sensual, material y, por qué no, constructiva y edilicia. Las técnicas de proyecto podrían crecer "en alcance, calidad e 
ingenio" si reconsideramos, uniendo la escucha sensible y una actitud crítica, tanto el contexto físico como las construcciones culturales. En ello toma parte el proyecto arquitectónico, saliendo al encuentro de todo aquello que aún necesita ser considerado, cuidado y acogido.
La arquitectura misma, imaginada como "edición de lo construido" -en un sentido amplio-, puede contribuir a crear imaginarios más comprometidos, hospitalarios y reflexivos, revalorizándose ella misma como herramienta cognitiva y pedagógica. 


\section{Bibliografía citada}

ALMONACID, Rodrigo. Mies van der Rohe, ¿mal interpretado o mal publicado? El caso del Seagram. En: Veredes. Arquitectura y Divulgación [en línea]. 21 de mayo de 2018 [consulta: 30-09-2020]. Disponible en: https://veredes.es/blog/mies-van-der-rohe-mal-interpretado-mal-publicado-caso-delseagram-rodrigo-almonacid/

ÁLVAREZ, Paula V. Un territorio común, casi olvidado. En: Francisco GONZÁLEZ DE CANALES, El manierismo y su ahora. Una aproximación optimista para un presente incierto. Sevilla: Vibok Works, 2020, pp. 72-103.

ARATA, Isozaki. Erasing architecture into the system. En: Cedric PRICE. Re: Cp. Luxemburgo: Springer Science \& Business Media, 2003.

AÑÓN-ABAJAS, Rosa María. La Bauhaus, de Dessau a Ulm: ensayos sobre el espacio docente de alto rendimiento/The Bauhaus, from Dessau to Ulm: essays on this high yield educational space. En: Proyecto, Progreso, Arquitectura. Sevilla: Editorial de la Universidad de Sevilla, 2010, n. ${ }^{\circ} 1$, pp. $26-45$. DOl https://doi.org/10.12795/ppa.2010.i1.02

CAMPBELL, R. Marking the End of 'The Bilbao Decade': Times Dictate a Shift Away from Vanity Projects. En: Boston Globe, 2009, vol. 11, p. 49-71. CORONADO, Diego. De la publicación de la fotografía a la fotografía publicada en torno a los orígenes decimonónicos de la fotografía publicitaria. En: Ámbitos. Revista Internacional de Comunicación, 2000, n. 3-4, pp. 221-245.

FERRANDO, Davide T. La ciudad en la imagen. Sevilla: Vibok Works, 2018.

GARCÍA-GERMÁN, Jacobo. Estrategias operativas en arquitectura. Madrid: Editorial Nobuko, 2012.

JAMESON, Fredric. The Political Unconscious: Narrative as a Socially Symbolic Act. Londres: Routledge, 1983.

JAMESON Fredric. Spatial Equivalents in the World System. En: Postmodernism, or the Cultural Logic of Late Capitalism. Londres: Verso, 1991, pp. $97-129$. LÓPEZ UJAQUE, José Manuel. Prefiriendo hacer (casi) nada en arquitectura: postproducción a través de cuatro declinaciones activamente perezosas. Director: Federico Soriano Peláez. Tesis doctoral. ETS Arquitectura, Universidad Politécnica de Madrid, 2017.

MIGUEL, Sergio de. Donde se rompen las nubes: Lever House, Nueva York 1950. Director: Javier Frechilla Camoiras. Tesis doctoral. ETS Arquitectura, UPM de Madrid, 2015. [Consulta 30-09-2020]. Disponible en: http://oa.upm.es/40369/

MUSCHAMP, Herbert. Critic's Notebook; Design Fantasies for a Strip of the West Side. The New York Times, 18 de octubre de 1999 [consulta: $30-09$ 2020]. Disponible en: https://www.nytimes.com/1999/10/18/arts/critic-s-notebook-design-fantasies-for-a-strip-of-the-west-side.html

PIZZA, Antonio. Peter Eisenman y la Ciudad de Cultura de Galicia, 1999-2011. En: DC Papers, revista de crítica y teoría de la arquitectura, 2010, n. 19, pp. 37-56.

PRICE, Cedric. Re: Cp. Luxemburgo: Springer Science \& Business Media, 2003.

PUENTE, Moisés; POYUELO, Anna, eds. 2G Book Lacaton \& Vassal. Barcelona: Editorial Gustavo Gili, 2007.

SLOTERDIJK, Peter. Esferas III, Madrid: Siruela, 2014.

STEYERL, Hito; BERARDI, Franco. Los condenados de la pantalla. Madrid: Caja Negra, 2014.

VASSAL, Jean-P.; RUBY, Andreas; RUBY, Ilka. Tabula non rasa. Ilka and Andreas Ruby in conversation with Jean-Philippe Vassal. En Ilka RUBY; Andreas RUBY, eds. Urban transformation. Berlín: Ruby Press, 2008, pp. 252-265.

WIGLEY, Mark. Towards a History of Quantity. En: Ole BOUMAN; Rem KOOLHAAS; Mark WIGLEY, eds. Volume 2: doing (almost) nothing. Ámsterdam: Archis, 2005.

WILSON, Robin. Evidence of “Doing Nothing”: The Utopic Document of Lacaton \& Vassal. En: Architectural Theory Review, 2013, vol. 18 , n. ${ }^{\circ}$ 1, pp. $30-45$.

Paula Victoria Álvarez Benítez (Sevilla, 1974). Arquitecta (ETSA de Sevilla, 2001). Coeditora y codirectora de la revista Neutra del COAS (2006-2010). Dirige y trabaja en Vibok Works desde 2010. Beca de investigación en materia de arquitectura de la Junta de Andalucía (2009-2012). Coautora Acciones Comunes (2014), Arquitectas y Shapes, Islands, text (2015) y editora y coautora de Arquitecturas Colectivas (2010), A la Luz de Hilberseimer (2016), La Ciudad en la Imagen (2018), El Manerismo y su ahora (2020), Arquitectura, crisis, crítica radical (2020). Contribuye regularmente en revistas académicas (Ábaco, Revista Sobre, LC Revue, Revista PPA) y de difusión y crítica de la arquitectura (Pasajes de Arquitectura y Crítica, Arquitectos, Neutra, Paisea, Metalocus, Volume). Actualmente es profesora colaboradora externa en el Departamento de Proyectos de la ETSA de Sevilla e invitada en el Máster de Imagen y Comunicación de la Arquitectura de la ETSA de Málaga. Premio FAD de Pensamiento y Crítica 2011. 
EDITAR VS. CONSTRUIR: UNA ECOLOGÍA DE LO INVISIBLE. AMPLIFICAR LA COMPRENSIÓN DE LAS TÉCNICAS DE PROYECTO

\section{EDITING VS. BUILDING: AN ECOLOGY OF THE INVISIBLE. AMPLIFYING THE UNDERSTANDING OF ARCHITECTURAL DESIGN TECHNIQUES}

Paula Victoria Álvarez Benítez (https://orcid.org/0000-0002-5628-4060)

p.53 INTRODUCTION

New York, 1998. Barely a year after the inauguration of the building which led to the term "decade of Bilbao"1 being coined the IFCCA convened the CCA Competition for the Design of the Cities, an international competition of ideas to improve the city through architecture ${ }^{2}$. Its aim was the urban requalification of a large area of Manhattan occupied by abandoned old railways, a natural point for loading and unloading to the Hudson River. Much of this site was occupied by a tangle of transport infrastructure: train tracks, upper motorway steps, tunnel entrances, bus parking... Conveners encouraged participants to go beyond convention to imagine new forms of urban experience, addressing a problem common to many cities: the gaps freed up by the vast outdated or decaying transport infrastructures, and isolated from urban life. But there was something else at stake. According to Herbert Muschamp, architecture critic for The New York Times, "city officials had already defined the site as the city's next great development corridor"3. Assessing the five finalist proposals, on display to the public at the time, he wrote: "With the exception of Mr. Price, the finalists share some common traits. All use curves or waves to set the site area off from the surrounding regularity of the Manhattan grid. With varying degrees of looseness, they adopt the megastructural approach: bringing together urban activities within a large, comprehensive architectural framework [...]"

p.54 In fact, Peter Eisenman's winning proposal opts, like three other finalists, for a great set of mixed and large-scale programmes that filled the lot, generating powerful and persuasive images ${ }^{5}$. Described by the architect as "the first urban icon of the new millennium", it takes the form of a sculptural ensemble of sensual wavy surfaces that rise from the horizontal plane to the monumental skyscraper which finishes off the intervention, intending to evoke the presence of the Hudson ${ }^{6}$ (figure 1). This is one of many telegenic architectural interventions designed to generate symbolic capital from visual impact and the spectacular form of technical solutions. That same year Eisenman won another contest following a similar strategy. Although it was never built, the City of Culture of Galicia created "a kind of delusional island" totally separate from the city of Santiago and "without any public infrastructure to connect with it"7.

However, today this competition is remembered for Cedric Price's proposal ${ }^{8}$. At the time of the launch of telegenic architecture as a global economic engine, the British architect took a step back, prioritizing enjoyment and the presence of the environmental and sensory qualities he discovered on site. The entire proposal revolved around the revaluation of the cool breeze from the Hudson which blew through the plot, and the open views, in short supply in a congested Manhattan (figure 2). He involved himself inventively with what was already there to highlight the value of architectural projects as care for the psychological well-being of inhabitants and, therefore, their health, aspects usually omitted from the imagery of the valuable by "enclave urbanism". The slogan of his proposal, "A Lung for Midtown Manhattan," has now taken on a different meaning following the crisis triggered by the COVID-19 health emergency. His profound motivation was to amplify the scope of the project concept, something which has now become essential.

Price was not alone in his critique of the assumptions around the role of architecture as an instrument for urban development. Shortly before, Lacaton \& Vassal, in their project for Léon Aucoc Square (1996), had proposed a strategy based on the attention and care of existing values. After the 2008 crisis, both proposals were vindicated as "non-intervention" or "anti-architecture" strategies", redeemed by their valuable criticism of the excesses of the media-focused architecture of the time. This interpretation has an undoubted pedagogical value at a point when

p.55 different promoters - public and private - are looking for iconic, spectacular, and signature buildings to attract financial capital. However, this is contradictory, as it allows the core of what these projects intended to reconsider to remain undiscussed: the identification between "spectacularism", "real estate product", "development" and "well-being". This article delves into the values of the projects obscured by this reading, which are linked to subtle attention and thoughtful work on existing and barely perceptible qualitative variables. The idea of "doing nothing", doing less, not intervening, or economy of means is insufficient, in our view, to account for this, as it assumes that "doing architecture" is nothing but "building". This premise hinders the understanding of these strategies and consequently limits their potential for application and development.

To clarify these issues, we will discuss the Bordeaux School of Business Administration by Lacaton \& Vassal (2006), where attention to qualitative aspects is not at odds with building. As in previous cases, the architects intervened in a built context where new relationships sensitive to existing values were laid down. We will also see how the habitual coding used to interpret specialized architecture - the type of planimetry, photography, or narrative - contradicts this approach $^{10}$. This will be done by contrasting the meanings promoted from various types of cultural media: specialized

p.56 publications aimed at architects and others aimed at a non-expert audience; those built by the architects themselves; architecture photography, and even "poor images"11 such as those taken by Google Street View or uploaded by users to Google Maps. Our interest in them lies in their detachment from the aesthetic coding assumed in specialized media, which tends to disconnect from the mundane, everyday life, and the lived experience of the built environment. It leads us to propose the search for an "ecology of the invisible", both in building projects and in urban intervention, an alternative approach to non-intervention from which to amplify the scope and inventiveness of architectural techniques. 
A LUNG FOR MANHATTAN, CEDRIC PRICE, 1998. VALUING THE EXISTING AND RESCUING THE FORGOTTEN In 1998 Price turned 64. He continued to emphasize "the importance of that which has been ignored or rejected" throughout his career. One of these aspects is context, which was dignified by taking it as raw material and not merely a background for new construction. Working as an "editor" of the urban landscape, Price had challenged the accepted image of the architect as an engineer and artist, genius inventor, and individual author ${ }^{12}$. In Manhattan, he promoted a semantic transformation of techniques. He thinks that what is at stake in the city cannot be solved by working only with material facts and experiences, but also with the symbolic surfaces that flood our daily life, shaping a particular culture that promotes certain forms of understanding, relationship, and enjoyment while inhibiting others. In this sense, Muschamp's article for The New York Times is the most comprehensive document among the limited literature on this project. While others jump to the conclusion of being faced with a "do-nothing" situation, the journalist records a multitude of specific actions: "Mr. Price's 'lung' essentially treats the place as if it were a rectangular nature preserve. Train tracks would remain uncovered. New development would be banned. Over time some existing buildings would be eliminated. The site would be marked with a sparkling covering composed of small glass spheres. The east and p.57 west boundaries would be fitted with tunnel-like structures that Mr. Price calls 'sleeves'. These would be places where people could go in any weather to contemplate the views of the city and the river. They would also channel air from the river into the heart of the city. A third observation post would be created by excising two floors from an existing building that straddle the tracks" 13

Rather than "do nothing" or "do less" he chooses to preserve and value its most outstanding and neglected characteristics through multiple small actions, which ultimately are the ones that amplify architecture, rather than the opposite. He decomposes the project into an examination of small measures which look at the many complex variables hiding behind what was referred to as "urban void" (Figures 2, 3, and 4). Price decided to leave the space "open" rather than "empty". He proposed the construction of an elevated tubular section promenade which would frame selected views thanks to the placement of various cabins. He included instructions for earth movement or patterns of runoff and drainage of the plot and symbolic actions alongside the existing infrastructures. These infrastructures included the tower from which the edges of the virtual volume of the "lost building" are laser-marked by real estate developers, and the humidity and temperature conditions were broadcast in real time. The views, the fresh air, or the train tracks themselves - their narrative quality as a memory of the place and its undefined character as "fallow" land - are qualitative aspects to be preserved and valued. By giving visibility to these insignificant variables, revealing them as unique and unrepeatable, he restores an essential and symbolic balance that concerns not only the concrete nature of the place but global culture - a context in which they are dismissed. In addition to a "nature preserve", he offers p.58 a preserve of "critical distance": an imaginative arsenal which draws attention to "the sophisticated role" that these "anecdotal and supposedly expendable elements can play within the environment and contemporary landscape" if we make them the focus of the architectural project, through accurate selection ${ }^{14}$. Instead of economizing on means, we find an "ecology of the invisible."

In the monograph that Hans Ulrich Obrist dedicated to Price in 2003, Arata Isozaki recalls the words that fellow member of the jury Philip Johnson addressed to him during the deliberations: "You'll no doubt recommend Cedric Price, and I agree, but if his proposal comes in first, the competition will forfeit all social significance. It's a pity!" 15 For the curator of the mythical Modern Architecture (1932) and Deconstructivist Architecture (1988), the social relevance of the competition lay elsewhere: in its ability to confirm the suitability of a particular image of architecture, seen as a symbol of a mode of practice and an appearance to be worked on. To make room for other possibilities, Price had to disassemble it, as shown by the panels submitted to the contest - a kind of cross between an instruction manual and a manifesto. The text predominates over the schematic and miniature drawings, with its own characteristic blunt and direct graphic style. Numerous photomontages and preparatory drawings (working documents rather than seductive images) express Price's interest in the uniqueness of the plot and its relation to the city (figures 2, 3, 4, and 5). About these, Muschamp writes: "Mr. Price's one-upmanship style extends to his mode of presentation. Instead of the glamorous computer renderings used by the other contestants, it offers rough pencil sketches that look as if they could have been dashed off on napkins between sips of clarets. Even the term 'sleeves' evokes drop-dead informality: custom tailoring of such exquisite refinement that a jacket turns out looking utterly shapeless. Yet the truth is that this design is the only one of the five that goes beyond the formal qualities of architecture to address the quality of urban life. Mr. Price's main concern, very simply, is with public health. It aims to improve the air, the amount of available light, and the psychological release that open space provides. It is, in effect, a park in which the archaeology of the industrial city takes the place of pastoral landscaping" 16.

Price's project methodology and schematic drawings certainly challenged the image of architecture that Johnson had helped forge. Modern Architecture, its catalogue, and the subsequent book The International Style (1932) laid the foundation for the current protocols of media treatment of architecture, in contrast to the intense editorial exploration 
of the architects exhibited ${ }^{17}$. These protocols are based on the separation of text and image and their isolation as an aesthetic phenomenon through "product photography": a commercial style based on the full-on and figure-centred point of view, a frame adjusted to eliminate context, preference for diaphanous daylight, without referring to life, work and daily tribulations ${ }^{18}$. The isolation of photography on the page reproduces the framing effect characteristic of

p.59 modern state museums, conceived to isolate artistic objects to generate an aura of solemnity and prestige around artistic objects $^{19}$. Reversing hierarchies that value what is useful to economic flows, instead of framing the architectural "object" in its panels, Price frames the views of the environment (figure 5).

The difference between the immersive reproduction of the inhabitant's experience in Price's only "view" (figure 4) and Eisenman's bird's-eye views (Figure 1) should be noted. Price confronts the use of renders and product photography as financial tools, as they tend to separate buildings from the material and social circumstances of their development. In his conscious departure from the implicit consensus of representation, he sets out and questions the logic of mediation and of the contest itself20. The panels recall a unique type of cartographic representation of 17th-century urban profiles, in which textual descriptions supplemented the aspects hidden from vision by the linked perspectives of multiple points of view at the height of the human eye (Figure 6). Price uses text to give visibility to everything that hegemonic rendering and storytelling styles and standards hide from vision. The panels are an inventory of minute tracks which confront the architectural imagination with what was being disconnected by chance. The intervention is conceived as an educational tool between the critical and the propositional. To do justice to what

p.60 was forgotten, Price relaunched it as a starting point.

LÉON AUCOC SQUARE, LACATON \& VASSAL, 1996. RECOVERING THE UNDERESTIMATED IN THE FACE OF THE NON-INTERVENTION INCONGRUITY.

Two years before this competition, Lacaton \& Vassal had presented a similar proposal for Léon Aucoc Square in Bordeaux (1996). The embellishment of this small triangular square was part of a larger urban project affecting 42 locations (figure 7). Lacaton \& Vassal - who begin every one of their works carefully examining whether the tasks and requirements of a commission are really needed ${ }^{21}$ - describe their first visit to the square thus: "When we came to see it, we were puzzled. For us, it was already beautiful the way it was. We could see neither how nor why we should 'embellish' it. In order to devise a meaningful intervention, we carefully started to study it. We analysed the architecture of the surrounding houses, the surface materials and urban furnishings of the square, the organization of traffic, and also interviewed the inhabitants. In the end, we only found minor misfits, none of which would have been solved by an architectural project"22.

Although they did not agree with this, Lacaton \& Vassal leave the identification between "construction", "product" and "project" that Price was trying to dismantle untouched. Their proposal is similar: to pay attention to the invisible and the forgotten. Vassal explains that they made "a catalogue of maintenance measures which were strikingly obvious and yet, completely unattended, including regularly cleaning the square of dog excrements, in order to make it possible to play the game of 'pétanque' (boules) on it once again; cleaning the linden leaves off the benches so that one could sit on them; rearranging the parking spaces; and reorganizing the traffic in order to reduce through-traffic. We also proposed the reintroduction of the St. John Fires, a customary public event which had previously been prohibited by city authorities in the name of security" 23 .

Among the measures proposed, the most striking is undoubtedly the last one, the vague proposal to revive the practice of lighting bonfires on the feast day of St. John. It goes even further than Price, encouraging reconnection with social phenomena and attention to the city's living conflicts ${ }^{24}$. This whole aspect was omitted in the description published on the architects' website ${ }^{25}$ and the monograph published by Gustavo Gili in $2007^{26}$. This may explain why

p.61 A Lung for Midtown Manhattan and Léon Aucoc were vindicated as ways of not-intervening and doing nothing, a redescription that "neutralizes" them. The relevant thing about both is the rescue of the forgotten and the underestimated; the attention paid to insignificant and vague aspects, barely noticeable, which everyone considered expendable except the architects, even when their strength is not legitimated and is unfoundedly architectural.

Robin Wilson has drawn attention to the aseptic way in which specialized media addressed a proposal as unique as that of Léon $\mathrm{Aucoc}^{27}$. The presentation rules set out in the monograph that 2G dedicated to the architects in 2002 dilutes the impact of the critical discourse of the office. However, various editorial inconsistencies reveal that something has been supressed. The first is the insistent use of the word "we" in the description of this project, breaking with the impersonal descriptions of the other 16 published projects. The second is the two photographs of the square, probably taken by the architects on a visit to the site. Their layout is similar to that of the photographs which Philippe Ruault took of the other projects. The third relates to the date of construction, 1996. Despite the insistence that the square "is beautiful as it is", it is emphasized that "something" has been done that is not building. These inconsistencies show the conflict between the recognition of the intellectual work and the rejection of strategy at the institutional level of editorial discourse. This conflict is expressed in the lay-out, also regulated, as it excludes and includes instruction on what is valuable and what is right ${ }^{28}$. Wilson does not mention another incongruence, which he is probably unaware of: the conscious and consensual suppression in the project's description of the fact that the architects produced a "catalogue of recommendations", including the political point of lifting the ban on the bonfires on the feast of St. John.

Touching upon Google Street View - a cultural document not ruled by the interests underlying the specialized mediation of architecture - we find a very different situation from that shown by these photographs from 1996. Vehicles 
have invaded the site, transforming it into a parking site (figure 8). The area intended for public use is limited to a minimal area on the shortest side of the square: a slide surrounded by benches and fenced off, possibly a cheap emergency measure to prevent it from being invaded by vehicles. What would have happened if, changing the social image of the square, popularly rooted activities such as the St. John bonfires had been allowed? What if the architects, instead of idealizing non-intervening, had redesigned the vegetation, furnishings, or pavement to regulate transit and preserve this area as open, public space? Like the frozen reality of the experience of the site visit, chosen to represent a simplified and appeasing version of the project, non-intervention also incongruously exposes the limits that the project imagination can resist: architecture is not an isolated phenomenon, but a system of choices that never turns out to be a frozen image, even if you choose not to carry it out. Rather than "revealing and maintaining the existing", the challenge would have been to "channel the rejected values" into the lived experience and the visible surfaces.

\section{THE SCHOOL OF BUSINESS ADMINISTRATION, LACATON \& VASSAL, 2006. FROM SENSITIVE ATTENTION TO THE EXISTING TO EDITING ARCHITECTURE}

The qualitative transformation of habitat is not strictly based on construction, but it is not necessarily in conflict with it either. This is the case of the School of Business Administration (2006), designed by Lacaton \& Vassal a decade later. The fragrant rose bushes in the backyards of the modest homes of workers adjoining the plot inspired its iconic enclosure. In the conversation with Ruby mentioned above, Vassal states: "[...] the project works absolutely in relation to its context by integrating and prolonging an essential aspect of its material reality: the gardens. The housing settlement, you see, consists of small worker's terraced houses from the 19th century. All of the houses have gardens which inform the character of the quarter, at least as much as the houses themselves. Interested in this vegetal quality of space, we noticed that there was a large quantity of rose trees in the gardens. Hence, we decided to 'floralize' our university building as well, placing 600 different rose trees throughout its outdoor spaces, such as the outdoor gallery and the interior courtyards. It is important to note that these trees are not only decorative but performative as well. Since the building was inaugurated in 2006, people who work in the university together with residents from the neighbouring housing quarter have come together and started to tend to the roses -and now they even produce a jam from the rose leaves!" 29 .

If in Léon Aucoc Lacaton \& Vassal rescued the supressed popular culture by urging the local administration to lift the ban on the St. John bonfires, here an ordinary event linked to habitation transforms the building. The urban skin is reinforced, evoking the uniqueness of the enclave, its cultural difference, the daily appeal to the senses and affections (figure 9). The profound value of Lacaton \& Vassal's work is not in its Povera aesthetic or its adscription to nondoing. Like Price's work, if falls under the category of qualitative work, where money cannot measure beauty, utility, or pleasure. The invisible aspects they rescue refer to psychological well-being, a condition that has become a luxury: it is difficult to access not because of its cost but because it is hard to see and appreciate. The official edition of this work proves it. Publishers, authors, critics, and photographers prefer to dilute these aspects in a form of self-censorship. Both the monograph and the website of the architects omit the origin of the façade solution, presenting it aseptically. The reinforcement that balanced the inevitable distance between technique and nature, between mechanics and vital spontaneity is reduced to contrasts: the delicate detail of the rose bushes contrasting with smooth technique. The Dionysian sign of the roses equates and is on a level with the Apollonian power of glass, avatar of scientific-technical discourse, of Reason. Human physical and emotional relationships disappear or become passive.

Vassal states that the "transfusion of context" into architecture originates from the desire to bring it closer to the city; Ruby calls it a "new contextualism". Rose bushes represent an attempt to overcome an opposing condition from which they fail to escape. By reducing the non-opposing link with context to naturalism, editorial mediation rules out the possibility of adding complexity to appearance, betraying the promises of experimental amplification of the scope of architecture. Ruault's profuse reporting of 44 photographs visually stages this disconnection (figure 10). Two represent the volumetry, 12 the interior spaces, and 30 the façade. Of the latter, 24 are taken either from the ground level - the level of access - directing the gaze upwards from a point near the façade, or from an elevated point. Thus, the street and context are removed from the "portrait" and the "story". The careful framing shows details of the roses, they aesthetize the motif and saturate our gaze with it. The chosen views and the photographic framing detach the building from the surroundings to the point of diluting the presence of the context, only recognizable in two of the 44 images. Significantly, they are taken from places located outside the free-space system: the courtyard and the side alley closed to the public. It seems as if the context should be avoided as well as erased from the plan. There is not a single plan showing the surrounding streets and the neighbourhood of the semi-detached houses with gardens, whose fragrant roses inspired the façade that has become an "image" of the work of the office, chosen for the cover of the monograph ${ }^{30}$

On both the pages of the $2 \mathrm{G}$ monograph and on the website ${ }^{31}$, the plans and sections float like islands (Figure 11). Once the erotic relationship of the building with the gardens of the context, users, and neighbours has been suppressed in the monograph and the web, it has also been removed as a didactic discovery, sealing the limits imposed on the imagination of architectural design. Again, Google Maps gives us access to more realistic images, but more truthful and connected to lived experience. Through it, we can fly over the lush gardens of the adjacent townhouse neighbourhood and sense the rose bushes that had enchanted the architects (Figure 12). Placing the viewfinder at street level, we sense why the perception of the building in its surroundings was discarded in the photographic report. 
The small houses of the workers have no special visual interest and are quite run-down: a condition which contrasts with the aesthetic codes of architectural photography.

On the ground floor, the glazed enclosure reflects these modest dwellings, whose presence cushions the impact of volume on the context. There is something poetic about this in spite of parked vehicles and garbage cans (Figure 13).

The reflection of the environment on the glazed façade is also perceptible in the "poor images" uploaded by users $^{32}$. We obtain access to the experiential, cultural, social, ecological, and anthropological aspects that Lacaton $\&$ Vassal achieve with the treatment of the façade. The luxury that editing denies us. The presence of rose bushes is much more discreet than Ruault's floral report - seemingly emulating the pre-construction renders (Figure 15) - seeks to imply. The aesthetic codes that govern its mediation dramatically spectacularize this detail, glamorizing a building of which we could also say that "it is already beautiful as it is".

If the symbolic city enters the courtyard through the transparencies of the dematerialized façade (Figure 9), here it is the everyday city that symbolically tarnishes architecture as it were. As the studio's website and specialized magazines dismantle such an attempt to amplify architecture, on the streets of Bordeaux, the façades of the School of Business Administration continue to tell a different story (Figure 15), warmer and more honest than its sweetened version.

\section{CONCLUSIONS. TOWARDS AN ECOLOGY OF THE INVISIBLE}

The search for an "ecology of the invisible" may be the setting for reconsidering project techniques to improve the built environment qualitatively. To defend this approach, an alternative to non-intervention, we initially relied on Herbert Muschamp's reading of the proposal A Lung for Midtown Manhattan and on Price's representation, which deconstructs a series of concrete actions relating to the attention to the values of the enclave and the city, exploring their capacity

p.67 to provide psychological enjoyment and well-being. These values refer to barely perceptible qualitative aspects, such as the sense of open space, the views, or the breeze through the plot. But they are also linked to pragmatic aspects, such as the proximity of the university, and symbolic ones, such as the refusal to fill the site with constructions. This last aspect is the basis of the interpretations (non-intervention, economy-of-means, anti-architecture...) that we try to reassess, since they can obscure the understanding of crucial aspects of project work as a sensitive display of critical attention.

In the analysis of Léon Aucoc Square and the Faculty of Business Administration by Lacaton \& Vassal, we have delved into both aspects, searching for the values involved in the "ecology of the invisible" and how the stories and specialized coding in use displaced them. These values would include sensory, environmental, cultural, and anthropological aspects that contribute to symbolically and erotically qualifying each particular site. The attention to cultural documents free from regulatory editorial coding such as Google Street View allowed us to show how such coding can meaningfully hinder the process of transference of information, savoir-faire, and the development of alternative techniques and models. By dismissing the ecology of the invisible, specialized media can devalue architecture, reducing it to the visual and technical display of its components, indifferent to subtle relationships with the social, cultural, geographical, and anthropological context.

Therefore, the "ecology of the invisible" should involve sensitive attention to the network of forces that impact a site, considering these to be working material: a resource with which to establish mutually rewarding connections. Besides, this would entail permanently rescue of hidden, invisible and forgotten elements - by promoters, the inhabitants, the city, or the architectural culture itself - to be welcomed in the conceptual, formal, sensory, material and, why not, constructive and building resolution. Project techniques could grow "in scope, quality and ingenuity" if

p.68 we reconsidered combining sensitive listening and a critical attitude, both physical context and cultural construction This also involves architectural projects embracing all that still needs to be considered, cared for, and welcomed. Architectural technique itself imagined as a form of "editing construction" - in a broad sense - can contribute to creating more committed, hospitable, and thoughtful imagery, recovering its value as a cognitive and didactic tool. $\square$

1. Robert Campbell came up with this term to designate the period between the opening of the Guggenheim in Bilbao (1997) and the bursting of the housing bubble (2008). CAMPBELL, R. Marking the End of "The Bilbao Decade": Times Dictate a Shift Away from Vanity Projects. In: Boston Globe, 2009, vol. 11, p. 49-71.

2. See: https://www.cca.qc.ca/en/archives/226652/ifcca-prize-competition-for-the-design-of-cities-fonds

3. MUSCHAMP, Herbert. Critic's Notebook; Design Fantasies for a Strip of the West Side. The New York Times, 18th October 1999. [Accessed 30-09-2020]. Available at: https:// www.nytimes.com/1999/10/18/arts/critic-s-notebook-design-fantasies-for-a-strip-of-the-west-side.html

4. Idem.

5. The other finalists were Thomas Mayne (Morphosis), Reiser + Umemoto RUR Architecture, Ben van Berkel and Caroline Boss. Muschamp. MUSCHAMP, H. op. cit. supra, note 3.

6. Available at: https://eisenmanarchitects.com/IFCCA-Prize-Competition-for-the-Design-of-Cities-1999

7. PIZZA, Antonio. Peter Eisenman y la Ciudad de Cultura de Galicia, 1999-2011. In: DC Papers, revista de crítica y teoría de la arquitectura, 2010, n. 19, pp. 37-56.

8. PRICE, Cedric. Re: Cp. Luxembourg: Springer Science \& Business Media, 2003, pp. 47-53.

9. See, for example, GARCíA-GERMÁN, Jacobo. Estrategias operativas en arquitectura. Madrid: Nobuko, 2012, pp. 242-265.; LÓPEZ UJAQUE, José Manuel. Prefiriendo hacer (casi) nada en arquitectura: postproducción a través de cuatro declinaciones activamente perezosas. Director: Federico Soriano Peláez. Doctoral thesis. ETS Arquitectura (Universidad Politécnica de Madrid), 2017. 
10. The editorial evolution of a high-impact magazine like El Croquis shows how editorial protocols in large print magazines and large digital platforms are conceived to support iconic status.

11. As cultural documents, they respond to what Hito Steyerl calls "poor images": images that, despite being discarded from commercial circulation due to poor quality and resolution below standards, are valuable as information tools. As they deal with actual conditions of existence, they make movements of awareness and affection possible. STEYERL, Hito; BERARDI, Franco. Los condenados de la pantalla. Caja Negra, 2014, pp. 33-68.

12. The detachable tent for 1200 spectators, built in three months for the Hair Theatre (1969), stands out as a precedent. Located between a canal and a stadium it used existing lighting, access control, and parking, while the canal boats were temporarily repurposed as dressing rooms. It also recovered the seats of a demolished Birmingham cinema and the steel structure of the construction waste piled up on a nearby site. This project can be found online at https://www.cca.qc.ca/en/archives/380477/cedricprice-fonds/396839/projects/407758/hair-tent

13. MUSCHAMP, Herbert, op. cit. supra, note 3 .

14. On this statement, see WIGLEY, Mark. Towards a History of Quantity. In: Ole BOUMAN; Rem KOOLHAAS; Mark WIGLEY, eds. Volume 2: doing (almost) nothing. Amsterdam: Archis, 2005.

15. ISOZAKI, Arata. Erasing architecture into the system. In PRICE, C., op. cit. supra, note 8, p. 46.

16. MUSCHAMP, Herbert, op. cit. supra, note 3.

17. See ÁLVAREZ, Paula V. Un territorio común, casi olvidado. In: Francisco GONZÁLEZ DE CANALES, El manierismo y su ahora. Una aproximación optimista para un presente incierto. Sevilla: Vibok Works, 2020, pp. 72-103.

18. This emerged in the early twentieth century as a commercial style for commercial catalogues. On the aesthetic and ideological basis of advertising photography, see CORONADO, Diego. De la publicación de la fotografía a la fotografía publicada en torno a los orígenes decimonónicos de la fotografía publicitaria. In: Ámbitos. Revista Internacional de Comunicación, 2000, n. ${ }^{\circ}$-4, pp. 221-245. In his criticism of specialized architecture photography, Fredric Jameson claimed that these were false images built to present it uncompromisingly as autonomous merchandise, subject to a process of commodification. JAMESON, Fredric. Spatial Equivalents in the World System. In: Postmodernism, or the Cultural Logic of Late Capitalism, London: Verso, 1991, pp. 97-129.

19. On the museum as a phenomena-isolator, see SLOTERDIJK, Peter. Esferas III. Madrid: Siruela, 2014

20. "None of the projects are officially authorized. None have clients. [...] Mr. Price chose not to go along with the impersonation. No massive new construction. No sports stadiums. No urban bone crunching. No high-tech structural calisthenics. No hay to be made. Just a light dusting of glass frosting and a breeze blowing from the river. Just a place for a city to breathe". MUSCHAMP, Herbert, op. cit. supra, note 3. Davide T. Ferrando reflects on the use of glamorous rendering in marketing strategies that start from architecture as a pure financial instrument. FERRANDO, Davide T. The city in the image. Sevilla: Vibok Works, 2018, pp. 193-236.

21. VASSAL, Jean-P.; RUBY, Andreas; RUBY, IIka. Tabula non rasa. Ilka and Andreas Ruby in conversation with Jean-Philippe Vassal. In Ilka RUBY; Andreas RUBY, eds. Urban transformation. Berlin: Ruby Press, 2008, pp. 252-265, p. 253.

22. Idem.

23. To make it clear that it was a proposal, they charged good fees for it. Ibid., p. 254.

24. The experimental architecture of the first decade of the $2000 \mathrm{~s}$ in Spain has continued to destabilize the imaginaries around the valuable through an ecology of the invisible. Examples of this can be found in the Hospedero and Nectarifero Garden Building by Husos Arquitectura (2012), the headquarters of Save the Children (2018), by Elii, or the Run Run Run and Remola restaurants, by Andrés Jaque / Office for Political Innovation (2019).

25. Lacaton \& Vassal [Accessed 09-30-2020]. Available at: https://www.lacatonvassal.com/

26. PUENTE, Moisés; POYUELO, Anna, eds. 2 G Book Lacaton \& Vassal. Barcelona: Editorial Gustavo Gili, 2007, p. 74.

27. WILSON, Robin. Evidence of "Doing Nothing”: The Utopic Document of Lacaton \& Vassal. In: Architectural Theory Review, 2013, vol. 18, n 1, pp. 30-45, p. 32. Wilson says systematic accreditation of architecture photographers denotes "that the building has been witnessed by an initiate of the canon, as if in a final act of signing-off the building as a perfectly realised product for global dissemination". This canon perpetuates generic standards that greatly reduce the scope of photography as an active agent in the interpretation of architecture. The start point of his analysis is JAMESON, Fredric. The Political Unconscious: Narrative as a Socially Symbolic Act. London: Routledge, 1983, where he urges seeking evidence of utopian impulse in the cultural forms of late capitalism in the face of "the systemic, cultural and ideological closure" of our current system. 28. For Wilson, the neutrality of the texts, with their descriptive and impersonal style "broadly reflect, or attempt to assume, the supposed position of the projects' illustrations, which, in the case of the completed projects, take the form of professionally-produced, large format photography-that is, they attempt to provide an 'objective' and 'neutral' portrait". WILSON, ibid., p. 36.

29. VASSAL, RUBY, RUBY, op. cit. supra, note 21, p. 256.

30. This not an isolated episode. Several authors have observed how the planimetry and photographs used to represent the Seagram reduce the complexity of the encounter with the environment, favouring the reading of the building as an opaque prism detached from the context. MIGUEL, Sergio de. Donde se rompen las nubes: Lever House, Nueva York 1950. Director: Javier Frechilla Camoiras. Doctoral thesis. ETS Arquitectura, UPM de Madrid, 2015. ALMONACID, Rodrigo. Mies van der Rohe ¿mal interpretado 0 mal publicado? El caso del Seagram. In: Veredes. Arquitectura y Divulgación [online]. 21st May 2018 [Accessed 30-09-2020]. Available at: https://veredes.es/blog/mies-vander-rohe-mal-interpretado-mal-publicado-caso-del-seagram-rodrigo-almonacid/. Rosa Añón observes how the representation of the Bauhaus has limited the understanding of "one of its main values: the territorial control it exercises in urban development". AÑóN-ABAJAS, Rosa María. La Bauhaus, de Dessau a Ulm: ensayos sobre el espacio docente de alto rendimiento/The Bauhaus, from Dessau to Ulm: essays on this high yield educational space. In: Proyecto, Progreso, Arquitectura, 2010, n. ${ }^{\circ} 1$, pp. 26-45, p. 27-29. D0I https://doi.org/10.12795/ppa.2010.i1.02

31. Lacaton \& Vassal [Accessed 30-09-2020]. Available at: https://www.lacatonvassal.com/index.php?idp=10

32. Erratic and fortuitous, these images present the building in context, confirming that the project strategy differs from what is published in the $2 \mathrm{G}$ monograph and the architects' website. They also prompt questions about the relationship between poverty, visibility, luxury, and vulgarity. 


\section{Autor imagen y fuente bibliográfica de procedencia}

Información facilitada por los autores de los artículos:

página 19, 1. WOODBRIDGE, Kenneth. Princely Gardens. Nueva York: Rizzoli, 1986; página 21, 2. ALPHAND, J. C. Adolphe. Les Promenades de Paris. Princeton: Princeton Architectural Press, 1984, p. 199; página 22, 3. AURICOSTE, Isabelle; TONKA, Hubert. Parc Ville Villette. Seyssel: Champ Vallon, 1987; páginas 23,24 y 25, 4, 5 y 6. Fotografías de Ramón R. Llera; páginas 26 y 27, 7 y 8 . BASSO PERESSUT, Luca; CALIARI, Pier Federico, eds. Piranesi Prix de Rome. Progetti per la nuova Via dei Fori Imperiali. Roma: Aión Edizioni, 2017; página 28, 9. LAB/PAP Laboratorio de Paisaje Arquitectónico, Patrimonial y Cultural; páginas 28 y 29, 10, 11 y 12 . BASSO PERESSUT, Luca; CALIARI, Pier Federico, eds. Piranesi Prix de Rome. Progetti per la nuova Via dei Fori Imperiali. Roma: Aión Edizioni, 2017; páginas 30 y 31 ,13, 14 y 15. ÁLVAREZ, Darío; IGLESIA, Miguel Ángel de la. Modelos de paisajes patrimoniales. Estrategias de protección e intervención arquitectónica. Valladolid: LAB/PAP y Departamento de Teoría de la Arquitectura y Proyectos Arquitectónicos, Universidad de Valladolid, 2017; página 36, 1. Philippe BOURDIN, “Le sacre de Louis XV", Histoire par l'image [en línea], consultado el 20 de agosto de 2020. Disponible en: http://histoire-image.org/fr/etudes/sacre-louis-xv; página 37, 2. Archivo de José lgnacio Linazasoro Rodríguez; página 38, 3. JAKOVUEVIC, Nada; CULOT, Maurice, dirs. Places et monuments. Bruselas: Mardaga, 1984; página 40, 4. RIGAUD, Olivier. Les plans anciens de Reims, 16001825. Dossier iconographique. Reims: RHA, 1991; página 41, 5. Biblioteca Municipal de Reims [en línea], consultado el 20 de agosto de 2020. Disponible en: https:// commons.wikimedia.org/wiki/File:Rue_Libergier_Cathédrale_Reims_Varin_30131.jpg; página 42, 6. Revista UR, 1985, n. ${ }^{\circ}$ 2; página 43, 44, 46, 47, 48, 49, 50, 7, 8, 9 , 10, 11, 12, 13, 14, 15. Archivo de José Ignacio Linazasoro Rodríguez; página 54, 1. Eisenman Architects Archives; página 55, 2. DR2004:0360:003 Cedric Price fonds Canadian Centre for Architecture; página 56, 3. DR2004:0355:007. Cedric Price fonds Canadian Centre for Architecture; página 57, 4. DR2004:0355:006. Cedric Price fonds. Canadian Centre for Architecture; página 59, 5. ARCH267828. IFCCA Prize Competition for the Design of Cities fonds Canadian Centre for Architecture; página 59, 6. Dominio público.; página 60, 7. Archivo Lacaton \& Vassal; página 61, 8. Fotomontaje de los autores a partir de Google Street View (2018); página 62, 9. Fotografía de Philippe Ruault:; página 63, 10. Muestra de la web del proyecto con el reportaje fotográfico de Philippe Ruault.; página 64,11 . Archivo Lacaton \& Vassal.; página 65,12 . Vista aérea en Google Maps (2018):; página 65, 13. Vista obtenida en Google Street View (2018); página 66, 14. Archivo Lacaton \& Vassal, 2004.; página 67, 15. Vista obtenida a través de Google Street View (2018); páginas 74 y 75, 1, 2 y 3. @ Krijn de Koning, cortesía del artista; páginas 76 y 77, 4, 5 y 6 . @ Jessica Stockholder, cortesía de la artista y de Mitchell-Innes \& Nash, Nueva York; páginas ,78 y 79, 7, 8 y 9. @ Katharina Grosse, VEGAP, Sevilla, 2021; páginas 82 y 83, 10 , 11 y 12. Heather Day website. Disponible en: https://heatherday.com/downtownoakland; página 90, 1. Universidad de Zaragoza. Unidad Técnica de Construcciones.; página 91, 2. Planimetría redibujada por Clara Dobón Ricarte.; página 92, 3. Planos, redibujada por Clara Dobón Ricarte. Fotografías cortesía de la Facultad de Derecho de la Universidad de Zaragoza.; página 93, 4. Google Maps.; página 94, 5. Fotografías de los autores.; página 95, 6. Proyecto de Ejecución, Ampliación y Reforma de la Facultad de Derecho (Zaragoza). Fuente: Universidad de Zaragoza. Unidad Técnica de Construcciones.; páginas 96 y 98, 7, 8. Planos y axonometría dibujados por Clara Dobón Ricarte; páginas 99 y 101, 9, 10, 11. Fotografías de los autores.; página 102, 12. Fotografía (izquierda) de los autores y fotografía (derecha) cortesía de la Facultad de Derecho de la Universidad de Zaragoza.; página 102, 13. Fotografías de los autores.; página 103, 14. Fotografía cortesía de Javier López Sánchez, decano de la Facultad de Derecho de la Universidad de Zaragoza.; página 104, 15. Proyecto de Ejecución, Ampliación y Reforma de la Facultad de Derecho (Zaragoza). Fuente: Universidad de Zaragoza. Unidad Técnica de Construcciones; página 108, 1. Dibujos del autor; página 109, 2. Ayuntamiento de Madrid; página 110 y 112, 3 y 4. Ayuntamiento de Madrid; página 113 y 114, 5 y 6 . Archivo Cabrero; página 115, 7. Reconstitución gráfica del autor; página 116, 8. Legado 2 Fundación COAM; página 117, 9. Dibujos del autor; página 118, 10. Arquitectura, 1959, n. 7 y Francisco de Asís Cabrero y Jaime Ruiz; página 119, 11. Archivo Cabrero; página 120, 12. Dibujos del autor; página 120, 13. Fotografía del autor; página 121, 14. Dibujos del autor; página 122, 15. Fotografía del autor. 

CITY. Darío Álvarez Álvarez • LINAZASORO EN REIMS. EL ESPACIO PÚBLICO COMO MEMORIA DEL LUGAR / LINAZASORO IN REIMS. THE PUBLIC SPACE AS THE MEMORY OF THE PLACE. Victoriano Sainz Gutiérrez • EDITAR VS. CONSTRUIR: UNA ECOLOGÍA DE LO INVISIBLE. AMPLIFICAR LA COMPRENSIÓN DE LAS TÉCNICAS DE PROYECTO / EDITING VS. BUILDING: AN ECOLOGY OF THE INVISIBLE. AMPLIFYING THE UNDERSTANDING OF ARCHITECTURAL DESIGN TECHNIQUES. Paula Victoria Álvarez Benítez • CUANDO LA PINTURA AMPLÍA LA ARQUITECTURA: INTERVENCIONES REALIZADAS EN EL ESPACIO PÚBLICO / WHEN PAINTING ENHANCES ARCHITECTURE: INTERVENTIONS IN A PUBLIC SETTING. Aurora Alcaide-Ramírez; Ana Ruiz-Abellón • UN EDIFICIO INVISIBLE. NUEVO AULARIO DE LA FACULTAD DE DERECHO DE LA UNIVERSIDAD DE ZARAGOZA (1983-1996) / AN INVISIBLE BUILDING. NEW LECTURE ROOM BUILDING OF THE FACULTY OF LAW OF THE UNIVERSITY OF ZARAGOZA (1983-1996). Luis Miguel Lus-Arana; Lucía Carmen Pérez-Moreno • ARQUITECTURAS AMPLIADAS. EL PABELLÓN DE EXPOSICIONES EN LA CASA DE CAMPO DE MADRID) / EXPANDED ARCHITECTURES. THE EXHIBITION PAVILION AT THE CASA DE CAMPO IN MADRID. José de Coca Leicher $\bullet$

- RAFAEL MONEO VALLÉS: LA VIDA DE LOS EDIFICIOS. LA MEZQUITA DE CÓRDOBA, LA LONJA DE SEVILLA Y UN CARMEN EN GRANADA . Víctor Pérez Escolano • FRANCISCO DE GRACIA: CONSTRUIR EN LO CONSTRUIDO. LA ARQUITECTURA COMO MODIFICACIÓN. Pablo Diañez Rubio • FRÉDÉRIC DRUOT, ANNE LACATON \& JEAN-PHILIPPE VASSAL PLUS: LA VIVIENDA COLECTIVA. TERRITORIO DE EXCEPCIÓN. Javier Terrados Cepeda.
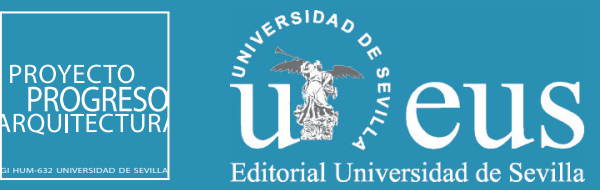